\title{
Continuum of care for HIV-positive women accessing programs to prevent parent-to-child transmission: Findings from India
}

Vaishali Sharma Mahendra

Population Council

Rupa Mudoi

Archana Oinam

Venkat Pakkela

Avina Sarna

Population Council

See next page for additional authors

Follow this and additional works at: https://knowledgecommons.popcouncil.org/departments_sbsr-hiv

Part of the Demography, Population, and Ecology Commons, Health Policy Commons, Immune System Diseases Commons, International Public Health Commons, Maternal and Child Health Commons, Medicine and Health Commons, Public Health Education and Promotion Commons, Virus Diseases Commons, and the Women's Health Commons How does access to this work benefit you? Let us know!

\section{Recommended Citation}

Mahendra, Vaishali Sharma, Rupa Mudoi, Archana Oinam, Venkat Pakkela, Avina Sarna, Sucheta Panda, Ashok Rau, L. Birendrajit Singh, and Naomi Rutenberg. 2007. "Continuum of care for HIV-positive women accessing programs to prevent parent-to-child transmission: Findings from India," Horizons Final Report. Washington, DC: Population Council. 


\section{Authors}

Vaishali Sharma Mahendra, Rupa Mudoi, Archana Oinam, Venkat Pakkela, Avina Sarna, Sucheta Panda, Ashok Rau, L. Birendrajit Singh, and Naomi Rutenberg 


\section{Hprizons}

\section{Continuum of Care for HIV-positive Women Accessing Programs to Prevent Parent-to-Child Transmission: Findings from India}

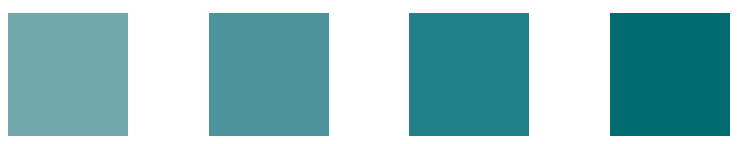

Horizons Program

Freedom Foundation

Social Awareness Service Organization 


\title{
Continuum of Care for HI V-positive Women Accessing Programs to Prevent Parent-to-Child Transmission: Findings from I ndia
}

\author{
Vaishali S. Mahendra ${ }^{1}$, Rupa Mudoi ${ }^{2}$, Archana Oinam ${ }^{3}$, \\ Venkat Pakkela ${ }^{2}$, Avina Sarna ${ }^{1}$, Sucheta Panda ${ }^{4}$, Ashok Rau ${ }^{2}$, \\ (Late) L. Birendrajit Singh ${ }^{3}$, and Naomi Rutenberg ${ }^{1}$
}
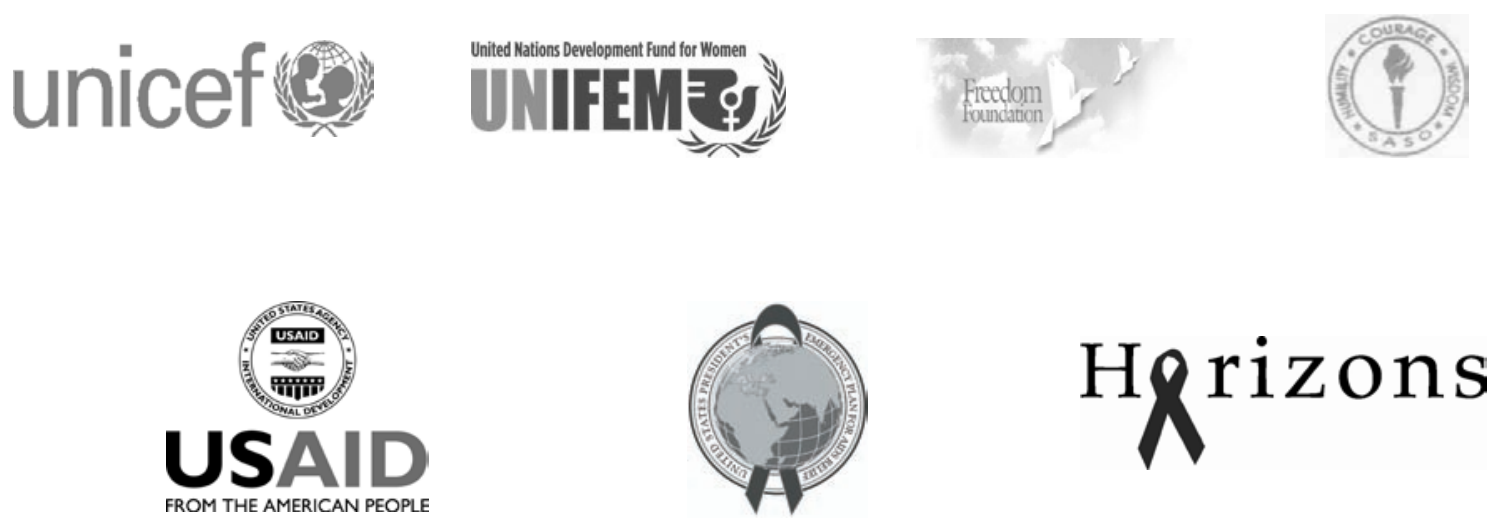

Institutional affiliations at the time of the study:

${ }^{1}$ Horizons/Population Council

${ }^{2}$ Freedom Foundation

${ }^{3}$ Social Awareness Service Organization

${ }^{4}$ Consultant, Population Council 


\section{Study Team}

\author{
Freedom Foundation, Bangalore \\ Ashok Rau \\ Rupa Mudoi \\ Sarvamangala S. \\ Krishnaveni R.
}

\author{
Social Awareness Service Organization, Imphal \\ (Late) L. Birendrajit Singh \\ Archana Oinam \\ Bangkim Chingsubam Singh \\ Basanta Kshetrimayun \\ N. Chandrajini
}

\author{
Horizons/Population Council, New Delhi \\ Vaishali Sharma Mahendra \\ Avina Sarna \\ Sucheta Panda, Consultant \\ Rajendra Prasad, Consultant
}

\author{
Freedom Foundation, Hyderabad \\ Ashok Rau \\ Venkat Pakkela \\ G.B. Mamtha \\ V.R. Sujatha \\ Francis Raj
}

\section{Horizons/Population Council, Washington, DC Naomi Rutenberg}

The study was funded by UNICEF India, UNIFEM India, and the President's Emergency Plan for AIDS Relief and the generous support of the American people through United States Agency for International Development (USAID) and the Horizons Program.

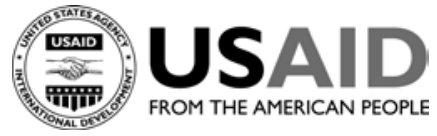

This research and final report were partly made possible by the President's Emergency Plan for AIDS Relief and the generous support of the American people through USAID under the terms of Cooperative Agreement No. HRN-A-00-97-00012-00. The contents are the responsibility of the Horizons Program and do not necessarily reflect the views of USAID or the United States Government.

Published in August 2007.

\section{(P) Population Council}

The Population Council is an international, non-profit, nongovernmental institution that seeks to improve the well-being and reproductive health of current and future generations around the world and to help achieve a humane, equitable, and sustainable balance between people and resources. The Council conducts biomedical, social science, and public health research and helps build research capacities in developing countries. Established in 1952, the Council is governed by an international board of trustees. Its New York headquarters supports a global network of regional and country offices.

Copyright (C) 2007. The Population Council Inc.

Suggested citation: Mahendra, Vaishali S., Rupa Mudoi, Archana Oinam, Venkat Pakkela, Avina Sarna, Sucheta Panda, Ashok Rau, L. Birendrajit Singh, and Naomi Rutenberg. 2007. "Continuum of care for HIV-positive women accessing programs to prevent parent-to-child transmission: Findings from India,” Horizons Final Report. Washington, DC: Population Council.

This document may be reproduced in whole or in part without permission of the Population Council provided full source citation is given and the reproduction is not for commercial purposes. 


\section{Acknowledgments}

This study would not have been possible without the collaborative efforts and hard work of many people. First, we would like to acknowledge the contributions of Vidhya Ganesh, Bir Singh, and Preeti Jha of UNICEF, and Suneeta Dhar and Vandana Mahajan of UNIFEM to the design and implementation of the study.

We would also like to express our thanks to the officials at the National AIDS Control Organization (NACO) for their support of the study. We wish to particularly thank the Project Directors of Karnataka State AIDS Prevention Society, Andhra Pradesh State AIDS Control Society, and Manipur State AIDS Control Society for their keen interest and technical guidance in developing and implementing the study in their respective states. We wish to acknowledge the support extended by the hospital administrators and managers of all the participating hospitals in the three study sites. Christopher Skill, Sharmila Hepzibah, Troy Cunnigham, and the team of counselors at Freedom Foundation in Bangalore and Hyderabad gave us their cooperation and support in conducting the study.

P. Kousalya (Positive Women's Network) and Ravi Verma (Horizons, Population Council) provided insightful inputs in the design of the research study. A special thanks to Shalini Bharat (Tata Institute for Social Sciences) for her inputs in designing the research tools. We would also like to thank Rajendra Prasad for providing assistance with data management. Special thanks to V.L. Thomas (Horizons, Population Council) for his excellent administrative support throughout the study. This report would not have been possible without careful review and editing by Ellen Weiss (Horizons, ICRW). For copyediting and formatting, we would like to thank Alison Lee (Consultant-Horizons, Population Council) and Sherry Hutchinson (Horizons, Population Council).

Most importantly, we would like to thank all the women, care providers, and program managers who participated in the research and gave us their valuable time and inputs. 


\title{
Abbreviations and Acronyms
}

\author{
AIDS Acquired immune deficiency syndrome \\ ANC Antenatal care \\ ANM Auxiliary nurse mid-wife \\ APSACS Andhra Pradesh State AIDS Control Society \\ ART \\ ARV \\ Antiretroviral therapy \\ AWW \\ Antiretroviral \\ CBO \\ Angan Wadi worker \\ EGPAF \\ Community-based organization \\ HIV \\ Elizabeth Glaser Pediatric AIDS Foundation \\ GFATM \\ Human immunodeficiency virus \\ MTCT \\ Global Fund for AIDS Tuberculosis and Malaria \\ NACO \\ NGO \\ NVP \\ Mother-to-child transmission \\ National AIDS Control Organization \\ Non-governmental organization \\ Nevirapine \\ PEPFAR President's Emergency Plan for AIDS Relief \\ PMTCT Prevention of mother-to-child transmission \\ PPTCT \\ $\mathrm{RCH}$ \\ SASO \\ SRH Sexual and Reproductive Health \\ Prevention of parent-to-child transmission (term used in India instead of PMTCT) \\ Reproductive and child health \\ UNICEF United Nations Children's Fund \\ UNIFEM United Nations Fund for Women \\ VCT \\ Voluntary counseling and testing
}




\section{Table of Contents}

\section{Abbreviations and Acronyms}

$\begin{array}{ll}\text { Executive Summary } & 1\end{array}$

$\begin{array}{ll}\text { Introduction } & 5\end{array}$

Rationale for a PPTCT-Plus Program in India $\quad 5$

$\begin{array}{ll}\text { Study aim and research questions } & 6\end{array}$

$\begin{array}{lr}\text { Methods } & 7\end{array}$

$\begin{array}{ll}\text { Research settings } & 7\end{array}$

$\begin{array}{lc}\text { Study design and data collection } & 8\end{array}$

$\begin{array}{ll}\text { Measures } & 10\end{array}$

Ethical issues $\quad 11$

Data management and analysis $\quad 11$

$\begin{array}{ll}\text { Results } & 12\end{array}$

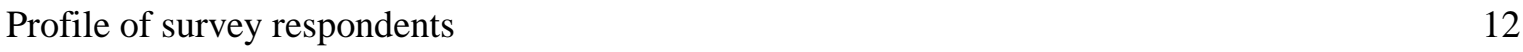

HIV testing and counseling $\quad 13$

Disclosure of HIV status and experiences $\quad 17$

$\begin{array}{ll}\text { PPTCT experiences } & 19\end{array}$

Antiretroviral prophylaxis for reducing vertical transmission $\quad 21$

HIV Treatment, care, and support $\quad 27$

Sexual and reproductive health 33

Enhancing linkages and improving access to services 44

$\begin{array}{ll}\text { Discussion and Recommendations } & 48\end{array}$

$\begin{array}{ll}\text { References } & 50\end{array}$

$\begin{array}{ll}\text { Appendix } & 51\end{array}$ 



\section{Executive Summary}

In India, 38.4 percent of the estimated 5.1 million HIV infections are among women (UNAIDS/WHO 2006). Although mother-to-child transmission (MTCT) accounts for a little less than 4 percent of all HIV infections in India, in sheer numbers it is the cause of approximately 56,700 children infected with HIV each year (IAP/NACO 2006, UNICEF 2006). With support from UNICEF, India's national program for prevention of parent-to-child transmission (PPTCT) of HIV has been underway since 2002. More recently, the government launched a national treatment program that offers antiretroviral therapy (ART) to HIV-positive women, children below 15 years of age, and men. However, since the start-up of the ART program there have been concerns about access to and utilization of these services by women and children. To address these concerns, a comprehensive PPTCT initiative that emphasizes treatment for HIV-positive women and their children was launched in 2004 by the National AIDS Control Organization (NACO) using funds from the Global Fund to Fight AIDS, Tuberculosis, and Malaria. To better implement this initiative, it is imperative to understand the prevention and care needs of the women who are receiving or have received PPTCT services, referral systems between PPTCT programs and other HIV-related and reproductive health services, and linkages between PPTCT programs and communitybased organizations and NGOs.

\section{Study Design and Methods}

In response to these needs, the Horizons Program, in collaboration with Freedom Foundation in Karnataka and Andhra Pradesh, and the Social Awareness Service Organization (SASO) in Manipur, undertook a diagnostic study in 2005 to provide an evidence base to strengthen the national PPTCT initiative. The key research questions were:

- What are the treatment, care, and support needs of HIV-positive women and what services do the women utilize to meet their needs?

- What are the different ways (clinic-based, community-based, etc) to link HIV-positive women and their families with treatment and care services?

The cross-sectional study used both qualitative and quantitative research methods and was carried out in Bangalore, Hyderabad, and Imphal — three cities located in the high HIV prevalence states of Andhra Pradesh, Karnataka, and Manipur, respectively. HIV-positive pregnant and postpartum women (0-24 months post-delivery) who were receiving PPTCT services from a purposive sample of public and private sector health facilities in the three cities were recruited to participate in in-depth (47) and structured (268) interviews. Service providers and program managers providing HIV-related services were also interviewed. All individuals provided informed consent prior to participation in the study.

\section{Characteristics of the Sample}

Overall, the combined mean age of the respondents was 25 years; women from Imphal were somewhat older than women from Bangalore and Hyderabad. Perhaps because they were older, women in Imphal had a higher mean number of pregnancies and a higher mean number of living children compared to women from the other two cities. The majority of women were currently married, but a higher percentage 


\section{Hgrizons}

of women from Imphal were widowed (22 percent) compared to women from the other two cities (Bangalore, 9 percent; Hyderabad, 4 percent). Financially, the majority of the households were lower to middle income. Among the pregnant women, over half were in the last trimester of pregnancy with an average gestation of seven months. About half (48 percent) of the 171 postpartum women had a delivery less than six months ago and about a third had a delivery between 6 and 12 months ago. The mean number of months postpartum was 9.2.

\section{Key Findings}

In Bangalore and Hyderabad, the vast majority of women were first tested for HIV as part of antenatal care (ANC), whereas in Imphal, most women were first tested in a voluntary counseling and testing (VCT) center. Obtaining informed consent prior to testing was not uniform across the cities; only 58 percent of women in Hyderabad were asked to give informed consent compared to 95 percent in Imphal. A very high proportion of women (90 percent) mentioned that their husbands (including those who were dead) had undergone HIV testing. Among the 239 currently married women, 73 percent reported that their husbands had tested HIV-positive, 16 percent had tested HIV-negative, and the remainder did not know their status or whether they had been tested. In most cases HIV test results were first disclosed either to the women or to the women and their husbands at the same time. But a fourth of the women reported that others, including husbands and parents, received the women's test results first.

Most of the women disclosed their HIV test results to their husbands and immediate family members. Only 13 percent of currently married women reported that their husbands did not know the women's HIV-positive status. The majority of the women did not regret their decision to share their test results with someone else. But some felt otherwise because they had experienced stigma and discrimination from family members. Analysis of scores from an adapted 20-item stigma scale revealed that the majority (66 percent) had a moderate level of internalized stigma and perceived interpersonal discrimination. But more than a fourth of the women had a high level of internalized stigma.

Nearly half of the pregnant women started ANC in their first trimester, half during their second trimester, and the remaining 14 percent during their third trimester. The majority of the pregnant women said they wanted to give birth to their children at the same health facility where they were receiving ANC services, mainly because these facilities knew about the women's HIV status and continued providing services to them.

When post-partum women were asked about the number of times they accessed ANC during their most recent pregnancy, 47 percent said six or more than six visits. Nearly two-thirds (65 percent) had a normal/vaginal delivery, 6 percent had a vaginal delivery with episiotomy, and 28 percent had a cesarean delivery. In Hyderabad, over half of the women reported they had undergone a cesarean delivery.

Almost all the women reported that their ANC provider informed them of medication they could take to reduce the risk of HIV transmission to their child during pregnancy, delivery, and infant feeding. More than a fourth of currently pregnant women were taking ARV prophylaxis during pregnancy. Almost all these women were receiving PPTCT services from the NGO-supported PPTCT program. The vast majority (84 percent) of postpartum women reported that they took medicine to reduce the risk of HIV transmission to their child. Most postpartum women took Nevirapine; 21 percent took AZT or 


\section{Continuum of Care for HIV-positive Women Accessing PPTCT Programs}

Zidovudine, which they started taking from 14-36 weeks of pregnancy. Of the postpartum women who had a live birth, 86 percent said their baby received/was provided medication.

About three-fourths (74 percent) of postpartum women with live births reported that they opted for replacement feeding, 19 percent for exclusive breastfeeding, and 7 percent for mixed feeding (breast feeding and replacement feeding together). Many women who opted for replacement feeding felt depressed at first for choosing not to breastfeed. But when they thought about the risk of transmitting HIV to their infants through breast milk, they accepted their choice of replacement feeding. Some women reported changing from their earlier chosen method of replacement feeding to breastfeeding because of family pressure and fear of being stigmatized for not breastfeeding. This often resulted in the women following mixed-feeding practices.

Overall, 41 percent of the women had ever heard of treatment for HIV or ART, and most of these women were from Imphal. Seven percent of all women $(n=19)$ were currently on ART. But more of the husbands were on ART than the wives. Among the 176 women with living, HIV-infected husbands, 28 percent of the spouses were on ART. Almost all of these men started ART prior to their wives, despite some husbands having been diagnosed after them.

Only two women mentioned that their PPTCT provider referred them to an ART facility. In general, ANC was not a good source of information about ART and how to access it; only 30 percent of women were informed about CD4 testing during ANC, and only 18 percent about ART.

Of the 211 women with living children, 38 percent had all their children tested for HIV and 18 percent had some of their children tested. One reason for not getting their children tested was that they were too young to undergo HIV antibody testing. One hundred and seventeen women reported that a total of 196 of their children were tested, of which 14 percent were HIV-positive. Many mothers who had their children tested did not know that HIV-positive children could take ART. Only two women had a child on ART.

Eight out of ten women received psychosocial and financial support from family members, particularly from husbands and parents. But a larger proportion (94 percent) received support outside the family, particularly emotional and psychological support from NGOs. Only 20 percent of respondents were members of a peer group. When women who were not members of a peer support group were asked if they would like to join one, more than a third (36 percent) said they would but close to half (48 percent) said they would not, mainly because they feared potential stigma if others found out they were members.

A substantial proportion (40 percent) of all women considered ending their pregnancy once they learned their HIV status. The main reason for wanting to end their pregnancy was the fear of transmitting HIV to their unborn child. Among the women who reported a pregnancy after their HIV status was diagnosed (n = 64), 44 percent said their recent or current pregnancy was not planned. The vast majority (87 percent) of all respondents did not want to have more children. Only 60 percent of the post-partum women who did not want to have more children reported using any family planning method. Most of the women who had undergone sterilization were advised to do so by their PPTCT provider. Eight out of ten pregnant women were advised by their PPTCT provider to use condoms to prevent re-infection; a smaller proportion of women (65 percent) reported actually using condoms. Qualitative data highlighted that condom use by women and their partners was often intermittent because the women felt that condoms were not necessary with their husbands or the husbands did not like condoms. 


\section{Hgrizons}

\section{Conclusions}

The study indicates that linkages between PPTCT and HIV care services, as well as PPTCT and reproductive health services, are limited. To address these shortcomings, the PPTCT programs studied should strengthen their referral systems to public and private treatment and family planning services, better equip PPTCT providers to inform and counsel women about these topics, and engage NGOs in the community who have outreach services to maintain contact with women over time and link them and their families to a continuum of care. 


\section{Introduction}

In recent years, there has been increasing concern about the lack of care and treatment services for HIVpositive women despite the high burden of HIV disease they bear. Current estimates indicate that women now account for almost 50 percent of the 38.6 million adults (aged 15-59 years) living with HIV worldwide, compared to 41 percent in 1997 and 35 percent in 1985 (UNAIDS/UNFPA/UNIFEM 2004). This shift has resulted in an increase in the number of HIV-infected women of reproductive age, which has further resulted in a rise in cases of pediatric AIDS.

To reduce vertical transmission of HIV from mothers to infants, prevention of mother-to-child transmission (PMTCT) programs have been implemented worldwide. PMTCT programs have been successful not only in reducing the risk of HIV transmission, but in encouraging people living with HIV to consider the possibility of having children. Health care providers in Uganda and India have reported that PMTCT programs have given hope to people living with HIV of having "HIV-free" babies (Rutenberg and Baek 2004).

Although PMTCT programs are focused on HIV-infected women of reproductive age, their key aim has been to prevent transmission of HIV from the mother to her child. These programs have tended to offer little care and support for the mothers themselves. The potential of PMTCT programs to serve as a key entry point to providing treatment and care to HIV-positive women and their families has not been given serious consideration, until recently.

\section{Rationale for a PPTCT-Plus Program in India}

In India, as per 2005 estimates, women accounted for 38.4 percent of the over 5 million HIV infections (UNAIDS/WHO 2006) ${ }^{1}$. A large proportion of these women are in the reproductive age group of 15-49 years which has implications for vertical transmission of HIV infection. It is estimated that 27 million women, including 189,000 HIV-positive pregnant women, give birth every year (UNICEF 2007). Although mother-to-child transmission (MTCT) accounts for less than 4 percent of HIV infections in India, without treatment, these newborns stand an estimated 30 percent chance of becoming infected during the mother's pregnancy, labor, or through breastfeeding after six months (NACO 2006, UNICEF 2006). This results in the birth of approximately 56,700 HIV-infected children every year (IAP/NACO 2006).

In 2002, the National AIDS Control Organization (NACO) initiated a national PMTCT program, which is now called the Prevention of Parent-to-Child Transmission (PPTCT) program. While the program has demonstrated the effective use of antenatal care (ANC) as an entry point to the prevention of vertical transmission, it has also identified a cohort of HIV-infected mothers without access to care and treatment. Therefore, there is an urgent need to design and implement policies and programs that provide an integrated continuum of care for these women and their families.

\footnotetext{
${ }^{1}$ The new 2006 estimates released by NACO (http://data.unaids.org/pub/PressRelease/2007/07/06), supported by UNAIDS and WHO, indicate that the national adult prevalence in India is approximately 0.36 percent, which corresponds to an estimated 2 million to 3.1 million people living with HIV in the country. These estimates are based on an expanded surveillance system and a revised enhanced methodology. However, as no further information is available on the new estimates from NACO (will be released later this year) we are using transmission rates for MTCT based on last year's estimates.
} 


\section{Hgrizons}

In 2004, NACO received funding from the Global Fund to Fight AIDS, Tuberculosis, and Malaria (GFATM) to actively link the PPTCT program with the national ART program (launched in April 2004) under which the key beneficiaries are: (i) HIV-positive women who access government antenatal clinics; (ii) HIV-positive children up to 15 years of age; and (iii) adults with full blown AIDS who access government hospitals for care and treatment (NACO 2004). The government recognizes that the delivery of a comprehensive range of services for HIV-positive persons requires an efficient follow-up system (e.g., clinical, psychosocial) and strengthened linkages with NGOs/CBOs for effective referrals, both for linking HIV-positive women to care centers and for linking women from care centers to communitybased support and care (personal communication with PPTCT consultant, NACO 2005). To inform the implementation of this initiative, it is important to better understand the needs of HIV-positive women who are receiving or have received PPTCT services, existing referral systems between PPTCT programs and other HIV-related and reproductive health services, and linkages between PPTCT programs and community-based organizations and NGOs.

\section{Study Aim and Research Questions}

In 2005 the Horizons Program, in collaboration with Freedom Foundation in Karnataka and Andhra Pradesh, and the Social Awareness Service Organization (SASO) in Manipur, undertook a diagnostic study to provide an evidence base to strengthen the national PPTCT initiative. The study was supported by UNICEF and UNIFEM and endorsed by NACO. The key research questions were:

- What are the treatment, care, and support needs of HIV-positive women and what services do the women utilize to meet their needs?

- What are the different ways (clinic-based, community-based, etc.) to link HIV-positive women and their families with treatment and care services?

The following issues were explored to answer the research questions:

- Health care-seeking behaviors of HIV-positive pregnant and postpartum women receiving PPTCT services.

- Factors influencing HIV-positive women's access and utilization of PPTCT, HIV care, and reproductive and child health (RCH) services.

- Referral systems for linking women with treatment and care services (e.g., for CD4 counts, family planning, etc.).

- Women's experiences of stigma, discrimination, and violence in family, community, and health care settings.

- Infant feeding options adopted by women and factors that influence their choices.

- Fertility intentions of HIV-positive women and access to family planning information and services. 


\section{Methods}

\section{Research Settings}

The study was conducted in Hyderabad in Andhra Pradesh, Bangalore in Karnataka, and Imphal in Manipur-three high HIV prevalence settings in India. Within each of the cities, an NGO was selected as the research partner because of their experience either with HIV/AIDS care and support activities or PPTCT service delivery.

In the cities of Hyderabad and Bangalore, Freedom Foundation was selected as the lead NGO partner. Since 2002, this NGO has been implementing a PPTCT program in private and public maternal and child health hospitals, which has been funded by the Elizabeth Glaser Pediatric AIDS Foundation (EGPAF). In Imphal, the Social Awareness Service Organization (SASO) was selected because they have a community-based treatment, care, and support program for HIV-positive women and their children, which links those in need to public sector PPTCT services. In addition to working with these two NGOs to facilitate recruitment of women receiving services through their program, efforts were also made to recruit women receiving PPTCT services from the government hospitals/centers in each of the three cities (Table 1). The main components of the EGPAF and National PPTCT services are detailed in Appendix 1.

In Bangalore, at the time this study was implemented, the Freedom Foundation's EGPAF-supported project was being implemented in 15 referral hospitals and maternity homes under the aegis of the Bangalore Mahanagar Palika or the Bangalore Municipal Corporation. In addition to these sites, permission was also granted by the Karnataka State AIDS Prevention Society to interview women receiving PPTCT services from the government sites. After contacting five sites, permission was granted to interview women from three government sites.

In Hyderabad, the Freedom Foundations’ EGPAF-supported project was being implemented in three private sector hospitals, from which women were recruited for the study. Four government PPTCT sites were also included in the study after seeking approval from the Andhra Pradesh State AIDS Control Society (APSACS). In these sites, the LEPRA Society (an eminent AIDS Service NGO in Hyderabad) was implementing a PPTCT outreach program with support from APSACS.

In Imphal, SASO was implementing community-based care and support programs for HIV-positive women and their children. While they did not provide PPTCT services, they referred pregnant women who were HIV-infected or spouses of HIV-infected men to the two public hospitals providing PPTCT services in the city. Thus, the two government hospitals implementing the PPTCT program were included in the study following approval from the Manipur State AIDS Control Society. 


\section{Hgrizons}

Table 1 Type and number of health facilities selected in each city

\begin{tabular}{lccc}
\hline Type of facility & Bangalore & Hyderabad & Imphal \\
\hline Government hospital with national PPTCT program & 3 & - & 2 \\
Government hospital with EGPAF-supported PPTCT program & 15 & - & - \\
Government hospital with national PPTCT program supported by & - & 4 & - \\
NACO partner NGO LEPRA) & - & 3 & - \\
Private hospital with EGPAF-supported PPTCT program & - & 3 \\
\hline
\end{tabular}

Conducting the research with these two NGOs in the selected health facilities in the three cities provided an opportunity to explore a range of health care needs, service delivery perspectives, and outreach experiences.

\section{Study Design and Data Collection}

The study used a cross-sectional design to collect data using both qualitative and quantitative research methods. Data were collected from July 2005 to February 2006.

Qualitative research with HIV-positive pregnant and post-partum women and with service providers and program managers preceded the quantitative research in order to inform the identification of the domains and the variables to examine in the survey instrument. For the qualitative phase, in-depth interviews were conducted with a total of $47 \mathrm{HIV}$-positive pregnant (14) and post-partum women (33) who were purposively selected for the study. These women were receiving PPTCT services from either Freedom Foundation in Bangalore and Hyderabad, or from the public sector in the three cities over the past two years.

In addition, 32 service providers and program managers of public sector or NGO-run PPTCT programs were interviewed to provide their perspectives on service delivery and access and utilization of services by HIV-positive women. The service providers selected included project directors heading PPTCT programs in the public and NGO sectors, doctors and counselors providing services to HIV-positive women and their families, and trained nurses, as well as traditional birth attendants providing services to women in the community.

In the quantitative phase, the research team interviewed $268 \mathrm{HIV}$-positive women who were pregnant or had an infant less than 24 months old and had participated in the PPTCT program. Between October 2005-January 2006, the counselors approached and contacted as many women as they could who fit these criteria during the women's follow-up visits to the participating hospitals. Once the women provided their consent to the counselors to participate in the study, the researchers then contacted them and, after providing more detailed information about the study, sought their written consent. Of all the women who were contacted for interviews in the three sites, only a few women did not consent to be interviewed, as they resided far away from the health facility and it would have been inconvenient for them to give time for the interview. The interviews were mostly conducted as per the woman's preference in the clinic or hospital in each of the three cities. Only in some cases were the interviews conducted in the woman's house. 
The main domains explored in the survey included HIV-infected women's treatment, care, and support needs; the types of services available to them and their families; and their access to and utilization of these services. In addition, the survey explored internalized stigma and experiences of discrimination, which reflected findings that emerged in the qualitative phase. Table 2 summarizes information about the different data collection methods.

Table 2 Data collection matrix

\begin{tabular}{|c|c|c|c|c|}
\hline Phase & Method & $\mathbf{n}$ & Respondents & Topic \\
\hline \multirow[t]{2}{*}{$\begin{array}{l}\text { Qualitative } \\
\text { research }\end{array}$} & $\begin{array}{l}\text { In-depth } \\
\text { interviews }\end{array}$ & 47 & $\begin{array}{l}\text { HIV-positive } \\
\text { pregnant (14) and } \\
\text { postpartum (33) } \\
\text { women }\end{array}$ & $\begin{array}{l}\text { HIV testing experiences, disclosure of result, } \\
\text { awareness about PPTCT and HIV treatment } \\
\text { services, accessing PPTCT services, } \\
\text { accessing HIV care and treatment services } \\
\text { for themselves and family, infant feeding } \\
\text { practices and decision making, care for the } \\
\text { child, fertility intentions of HIV-positive } \\
\text { women and access to family planning } \\
\text { information and services, stigma and } \\
\text { discrimination, suggestions for expanding } \\
\text { their access to HIV and SRH services }\end{array}$ \\
\hline & $\begin{array}{l}\text { Key-informant } \\
\text { interviews }\end{array}$ & 32 & $\begin{array}{l}\text { Project directors, } \\
\text { program managers, } \\
\text { counselors, outreach } \\
\text { workers, auxiliary } \\
\text { nurse midwives } \\
\text { (ANM), Angan Wadi } \\
\text { workers (AWW), } \\
\text { traditional birth } \\
\text { attendants }\end{array}$ & $\begin{array}{l}\text { Perception of HIV-positive women's health } \\
\text { needs for themselves and their families, } \\
\text { experiences in providing PPTCT services, } \\
\text { gaps in PPTCT services, need for expanding } \\
\text { services to link with HIV treatment and SRH }\end{array}$ \\
\hline $\begin{array}{l}\text { Quantitative } \\
\text { research }\end{array}$ & $\begin{array}{l}\text { Survey - } \\
\text { structured } \\
\text { questionnaire }\end{array}$ & 268 & $\begin{array}{l}\text { HIV-positive } \\
\text { pregnant women (97) } \\
\text { and postpartum } \\
\text { women (171) }\end{array}$ & $\begin{array}{l}\text { HIV testing and counseling for self, partner, } \\
\text { and child; disclosure of result; access to } \\
\text { ANC and PPTCT; PPTCT experiences; } \\
\text { awareness of and access to HIV treatment } \\
\text { services for self, partner, and child; infant } \\
\text { feeding practices and decision making; HIV } \\
\text { care and support; pregnancy decision } \\
\text { making and outcomes; fertility intentions and } \\
\text { access to family planning information and } \\
\text { services; self-stigma; discrimination; } \\
\text { violence }\end{array}$ \\
\hline
\end{tabular}




\section{Hgrizons}

\section{Measures}

To measure internalized stigma and perceived interpersonal discrimination, the research team first field tested the 40-item Berger HIV Stigma Scale (Berger 1996) with 15 HIV-positive women for clarity and understanding. Based on their responses and feedback from the investigators, 20 items were selected for use in this study (see Box 1). Responses were scored on a four-point Likert scale ranging from Strongly Agree to Agree to Disagree to Strongly Disagree. Two items (3 and 11) were reverse scored so that all responses that were Strongly Disagree were scored as 4 and Strongly Agree as 1 (with Agree scored as 2 and Disagree scored as 3). The total scores ranged from a minimum of 30 to a maximum of 76, with a higher score indicating a higher level of internalized stigma and perceived interpersonal discrimination. Scores were trichotomized as low, moderate, and high self-stigma in order to characterize the stigma levels of respondents.

\section{Box 1 Selected 20 items from the Berger scale to measure internalized stigma and perceived interpersonal discrimination among HIV-positive pregnant and postpartum women}

I. This set of questions asks about some of your feelings and opinions as to how you feel when people treat you or react to you because of your HIV status. Please do your best to answer each question. For each item, circle one response: Strongly disagree (SD), Disagree (D), Agree (A), or Strongly Agree (SA)

1 I feel guilty because I have HIV.

2 People with HIV lose their jobs when their employers find out.

3 I never feel ashamed of having HIV.

4 People with HIV are treated like outcasts.

5 Since learning I have HIV, I feel set apart and isolated from the rest of the world.

6 Having HIV makes me feel that I'm a bad person.

7 Most people with HIV are rejected when others find out.

8 I am very careful who I tell that I have HIV.

9 Since learning I have HIV, I worry about people discriminating against me.

10 Most people are uncomfortable around someone with HIV.

11 I never feel the need to hide the fact that I have HIV.

12 I worry people may judge me when they feel I have HIV.

II. Many of the items in this next section assume that you have told other people that you have HIV, or that others know. This may not be true for you. If the item refers to something that has not actually happened to you, please imagine yourself in that situation. Then give your answer ("SD," "D," "A," "SA") based on how you think you would feel or how you think others would react to you.

13 I worry that people who know I have HIV will tell others.

14 Some people avoid touching me once they know I have HIV.

15 People have told me that getting HIV is what I deserve for how I lived my life.

16 People have physically backed away from me when they learn I have HIV.

17 People don't want me around their children once they know I have HIV.

18 I have lost friends by telling them I have HIV.

19 I have told people close to me to keep the fact that I have HIV a secret.

20 People seem afraid of me once they learn I have HIV. 


\section{Ethical I ssues}

All persons participating in the qualitative interviews and the survey provided informed consent. The research team used a two-stage consent process to recruit HIV-positive women. First, the NGO and public sector service providers (who knew the client's HIV status) briefly introduced the study to the women when the women visited the clinic for their follow-up visit. They asked the women whether they would be willing to meet with an interviewer to get additional details about participating in the study. A written statement was provided by the research team to the service providers so that in all sites the same information was provided to the potential respondents. If a woman agreed to meet the interviewer, a time and place convenient to her was fixed and the research team was informed. One of the research team members then met the woman at the scheduled time and place to provide more detail about the study and obtain written consent to participate in the study. At this time the researcher explained the purpose of the study, and informed participants that they can refuse to be interviewed or participate in the interview or terminate the interview at any time without any negative repercussions. The participants read the consent form and, if they agreed to be interviewed, signed it. In the case of illiterate persons, the interviewer read the form to the participants and indicated on the form whether the participants provided verbal consent. Interviewers obtained informed consent from the respondents prior to starting interviews.

All interviews were held between the interviewer and respondent in a private area, so that the information provided could not be overheard. The research team considered confidentiality an utmost concern in the collection, management, and analysis of all data collected. All audiotapes and notes were kept in a locked filing cabinet. Names of the study participants were not recorded on any written or electronic data collection forms or archives. Nobody outside the core research team and those providing technical assistance on this project had access to the data in any format.

The study protocol was reviewed by the Population Council's Institutional Review Board for ethical approval to the study. The partner NGOs had consultations with their board members and, upon their approval and the Council's approval, the study was started in the three sites.

\section{Data Management and Analysis}

Qualitative research data were transcribed into detailed notes by the researchers following the interview. These transcripts were then translated from regional languages into English and then typed up in Microsoft Word. Emerging themes were extracted and coded using ATLAS.ti. Coded data were analyzed by all the research team members.

For quantitative data, a data management specialist set up the frames for data entry. Double data entry was undertaken for ensuring accuracy. The data management expert monitored quantitative data entry, and one in every five questionnaires was verified against the original data entry. Quantitative data were analyzed using the SPSS 11.0 data analysis software. Quantitative data from the sites in each city have been combined and presented. As the study is exploratory in nature and because of inherent differences in the number and type of sites in each city, statistical tests of associations have not been conducted to highlight differences or similarities across the three cities. 


\section{Hgrizons}

\section{Results}

\section{Profile of Survey Respondents}

As shown in Table 3, the combined mean age of the 268 respondents was 25 years (range 18-38 years). Women from Imphal were, on average, older than women from Bangalore and Hyderabad. The majority of women from all three sites were currently married, but a higher percentage of women from Imphal were widowed (22 percent) compared to women from Bangalore (9 percent) and Hyderabad (4 percent). Women in Imphal also had a higher mean number of pregnancies and a higher mean number of living children compared to women from Bangalore and Hyderabad.

More than half (57 percent) of the survey respondents had between six and twelve years of schooling while close to a quarter were illiterate. Once again, there were differences across the study sites; women in Imphal tended to be more educated than their counterparts in the other sites. Irrespective of the difference in educational status across sites, the majority of women in the three sites were unemployed. Of the 189 unemployed women, over half (57 percent) had never worked and the rest (43 percent) mentioned that they had to leave their job due to a lack of child care at home, pregnancy status, or illness.

Table 3 Characteristics of survey participants by city

\begin{tabular}{lcccc}
\hline & $\begin{array}{c}\text { Bangalore } \\
(\mathbf{n = 1 0 8 )}\end{array}$ & $\begin{array}{c}\text { Hyderabad } \\
(\mathbf{n}=\mathbf{9 5})\end{array}$ & $\begin{array}{c}\text { Imphal } \\
(\mathbf{n}=\mathbf{6 5})\end{array}$ & $\begin{array}{c}\text { Total } \\
(\mathbf{n}=\mathbf{2 6 8})\end{array}$ \\
\hline Mean age (in years) & 24 years & 22 years & 30 years & 25 years \\
Marital status (\%) & & & & \\
$\quad$ Currently married/cohabiting & 91 & 96 & 78 & 90 \\
$\quad$ Widowed/separated & 9 & 4 & 22 & 10 \\
Mean number of pregnancies & 2.2 & 2.0 & 2.3 & 2.1 \\
Mean number of living children & 1.4 & 1.4 & 1.8 & 1.5 \\
Education (\%) & & & & 23 \\
$\quad$ Illiterate & 21 & 34 & 8 & 9 \\
$\quad$ Up to 5 years of school & 12 & 8 & 6 & 57 \\
$\quad$ 6 to 12 years of school & 62 & 44 & 69 & 11 \\
$\quad$ Graduation and above & 5 & 14 & 17 & 29 \\
Employment (\%) & & & & \\
$\quad$ Employed & 25 & 28 & 38 & \\
\hline
\end{tabular}

Women were also asked about their husband's demographic characteristics. For all of the women, the husband's mean age was 31 years (with a range of 21-48 years). Over three-fourths of the husbands had completed more than six years of schooling and over 90 percent were currently employed.

When women were asked about their household monthly income, close to half reported an income of less than Rs 2,000 (or USD45) followed by a fourth who said between Rs 2,000 to Rs 4,000. Based on these figures, the majority of the households would be categorized as between lower to middle income. 
The 47 HIV-positive women who participated in the in-depth interviews had a similar profile to the survey respondents. The vast majority (41) were married, three were separated from their partners and three were widows. The women were an average age of 25.9 years, with a median of 25 years. They had an average of 2.6 pregnancies and the mean number of living children was 1.5.

\section{HIV Testing and Counseling}

When women were asked about their HIV testing experiences, close to three-fourths mentioned they were first tested as part of ANC. The majority of these women reported being tested in a public sector facility. However, in Imphal, unlike in Bangalore and Hyderabad, almost all of the respondents were first tested in a voluntary counseling and testing center managed by an NGO (see Table 4).

Table 4 Site where HIV test first conducted

\begin{tabular}{lcccc}
\hline & $\begin{array}{c}\text { Bangalore } \\
(\mathbf{n = 1 0 8 )} \\
\text { \% }\end{array}$ & $\begin{array}{c}\text { Hyderabad } \\
(\mathbf{n = 9 5 )} \\
\mathbf{9}\end{array}$ & $\begin{array}{c}\text { Imphal } \\
(\mathbf{n = 6 5}) \\
\%\end{array}$ & $\begin{array}{c}\text { Total } \\
(\mathbf{n = 2 6 8 )} \\
\mathbf{\%}\end{array}$ \\
\hline ANC in district/state/MCH hospital & 76 & 47 & 5 & 49 \\
ANC in private hospital & 20 & 47 & - & 25 \\
Voluntary counseling and testing center & 2 & 5 & 91 & 25 \\
Others (private lab) & 2 & - & 4 & 1 \\
\hline
\end{tabular}

The duration of knowing about their HIV status varied across the three cities. Two-thirds of women in Bangalore and Hyderabad learned that they were HIV-positive less than a year ago compared to only a fourth of the women in Imphal. The majority (71 percent) of the women in Imphal were diagnosed over a year ago (see Figure 1). 


\section{Hgrizons}

Figure 1 When HIV status first diagnosed

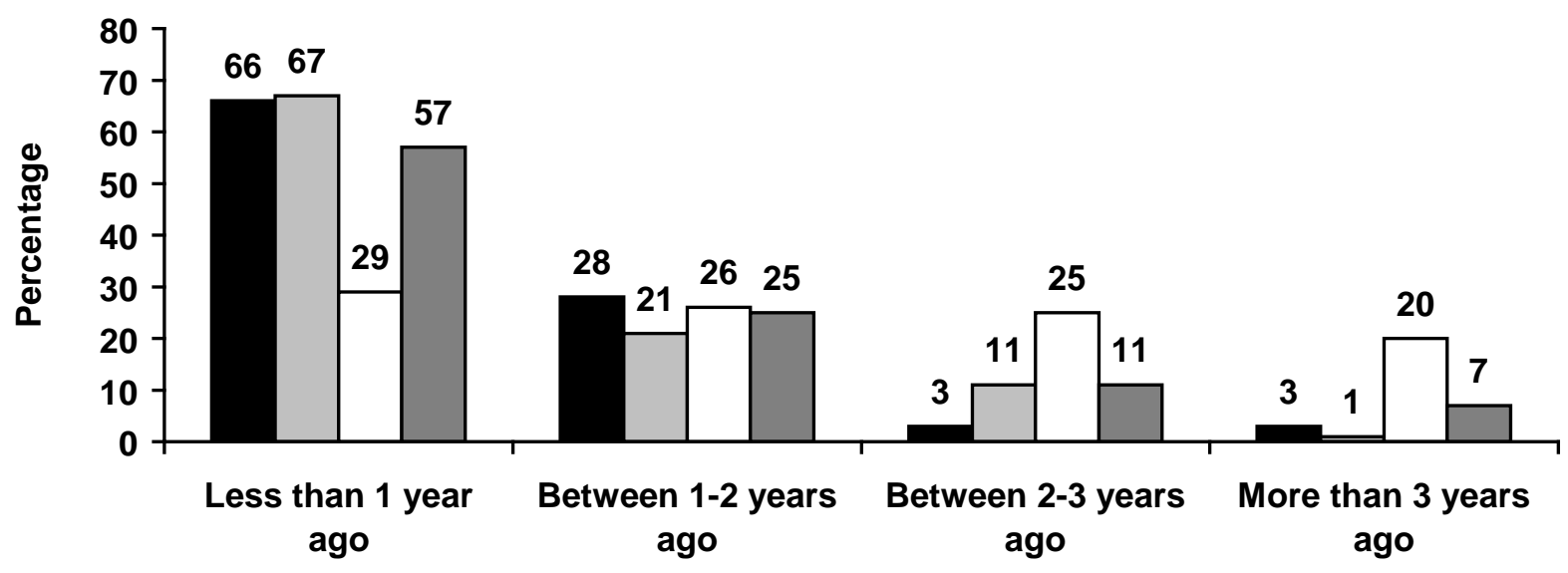

Bangalore $\quad \square$ Hyderabad $\quad \square$ Imphal $\quad$ CCombined sites

Overall, three-fourths of the women mentioned that they gave informed consent prior to their HIV test, but this varied by city. Fewer women in Hyderabad (58 percent) reported giving informed consent compared to Bangalore (82 percent) and Imphal (95 percent). This may be due to the fact that almost half of the women in Hyderabad were first tested in a private hospital where pre-test counseling and informed consent may not be consistently practiced. Most of the women who reported giving informed consent also mentioned receiving pre-test and post-test counseling.

When the women were asked about the number of times they had been tested for HIV, nearly half (46 percent) mentioned undergoing an HIV test two or more times. Women from Hyderabad were the most likely to have gotten an HIV test more than once (see Figure 2). 
Figure 2 Number of times HIV test conducted

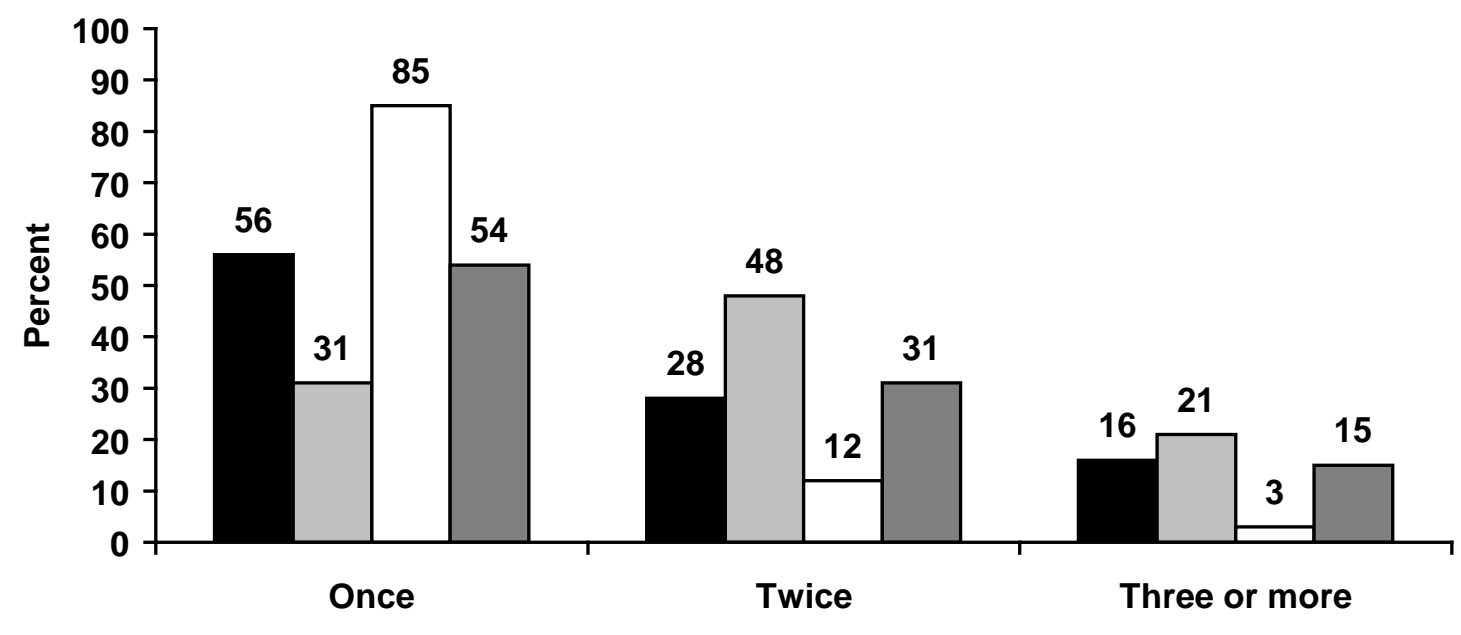

Eangalore $\square$ Hyderabad $\square$ Imphal $\square$ Combined sites

Of the 123 women who were tested more than once, the most commonly cited reasons included wanting to confirm their status and hospital requirements. When probed further about the reasons, most of these women mentioned that their first test was done in a hospital different from the one in which they were recruited for this study; the initial hospital refused to treat them once they were diagnosed as HIVpositive. Consequently, they went to another hospital where they did not necessarily disclose their status; thus, they were tested again for HIV. Some also mentioned that they could not believe their first test result and got another test to confirm their status.

I was first detected at a private hospital that refused to take my case when my test came positive. They referred me to the government hospital. Here I was again tested for HIV to confirm my status.

HIV-positive pregnant woman

...as I didn't reveal my test result to the hospital, I was tested again for HIV.

HIV-positive postpartum woman

Ninety percent of all women ( $\mathrm{n}=268$ women including the 24 women whose husbands were dead) reported that their husbands had undergone HIV testing. The remaining 10 percent said their husbands had not tested or they did not know if they had gotten an HIV test. Of the women whose husbands had been tested $(n=242)$, the partner who had been tested first varied by city; the vast majority of women in Bangalore and Hyderabad had been tested before their husbands whereas the opposite was true in Imphal (see Table 5). 


\section{Hgrizons}

Table 5 When husband tested for HIV (of those women whose husbands were tested)

\begin{tabular}{lcccc}
\hline & $\begin{array}{c}\text { Bangalore } \\
(\mathbf{n = 9 5 )} \\
\mathbf{\%}\end{array}$ & $\begin{array}{c}\text { Hyderabad } \\
(\mathbf{n = 9 0 )} \\
\mathbf{\%}\end{array}$ & $\begin{array}{c}\text { Imphal } \\
(\mathbf{n}=\mathbf{5 7}) \\
\mathbf{\%}\end{array}$ & $\begin{array}{c}\text { Total } \\
(\mathbf{n}=\mathbf{2 4 2}) \\
\mathbf{\%}\end{array}$ \\
\hline Husband tested before me & 10 & 13 & 77 & 27 \\
Husband tested after me & 86 & 82 & 16 & 68 \\
Husband tested at the same time as me & 4 & 3 & 7 & 7 \\
\hline
\end{tabular}

The reason for this appears to be that in Bangalore and Hyderabad the majority of the women were tested for HIV in the PPTCT site and were then counseled to bring in their husbands for HIV testing. In these cases, the men were usually tested after the women. However, in Imphal, most of the women participating in in-depth interviews mentioned that their husbands had been injecting drug users and had therefore undergone HIV testing as part of harm reduction programs implemented by various NGOs in the city. Once the men learned their status they were counseled to disclose their status to their female partners or wives and refer them to the NGO or a VCT center for HIV testing.

I knew my husband was an injecting drug user. My husband has very good friends working at the NGO. After consulting with them personally we decided to get me tested. I was quite prepared for the positive result. We discussed a lot before going for the test. I got myself tested at the VCT in the hospital and was found to be positive.

HIV-positive pregnant woman from Imphal

My husband was positive [used to inject drugs] and he wanted to do the testing for me as I was pregnant. Because of him only I did the testing.

HIV-positive postpartum woman from Imphal

My husband was very sick. The hospital doctor did the testing and he was found to be positive. He became well soon after starting the treatment. There is also a doctor from our community in Imphal. He talked to us and under his advice I got tested. I was also found to be positive.

HIV-positive pregnant woman from Imphal

Nearly three-fourths of the 239 currently married women (excluding women who were widowed/separated/abandoned) reported their husband had tested HIV-positive (see Figure 3). 
Figure 3 HIV serostatus of married women's husbands $(n=239)$

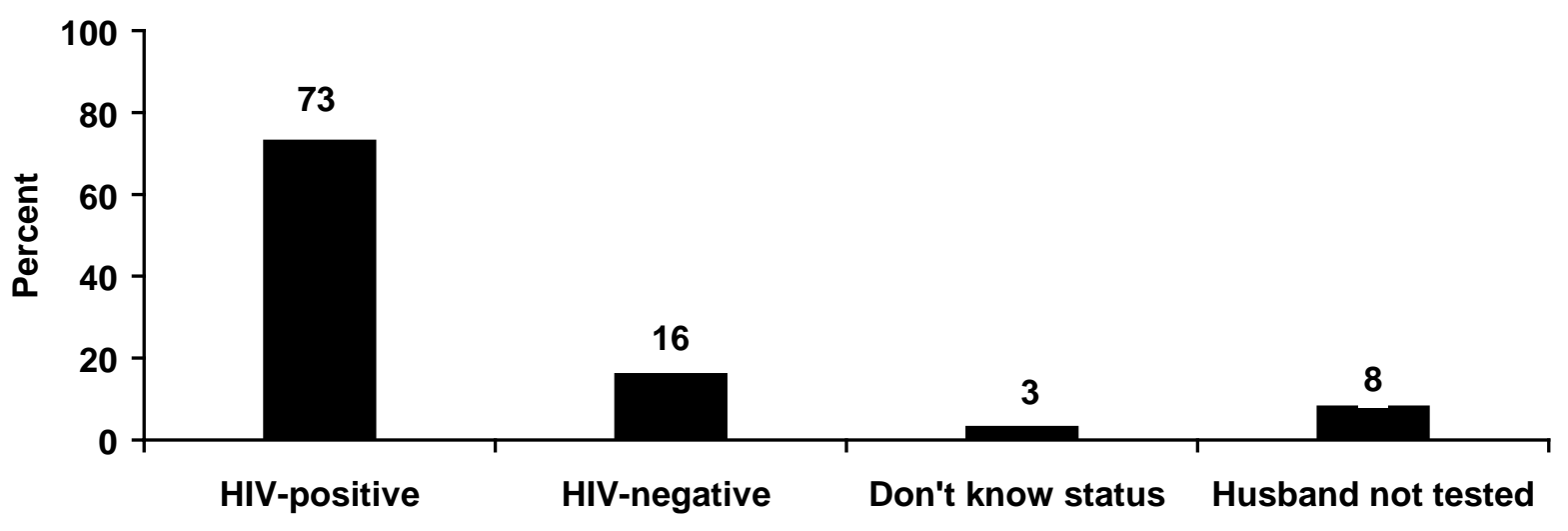

\section{Disclosure of HIV Status and Experiences}

When asked who was first informed of their HIV test result, 46 percent of the respondents mentioned they were. About a fourth of the women reported they were told jointly with their spouse. But an additional 25 percent of women reported that others, including husbands and parents, were informed about their status before they were. As shown in Figure 4, there were differences across cities; only a third of women in Imphal and Hyderabad were told their test results first compared to close to three-fourths in Bangalore.

\section{Figure 4 Person informed first about woman's HIV-positive status}

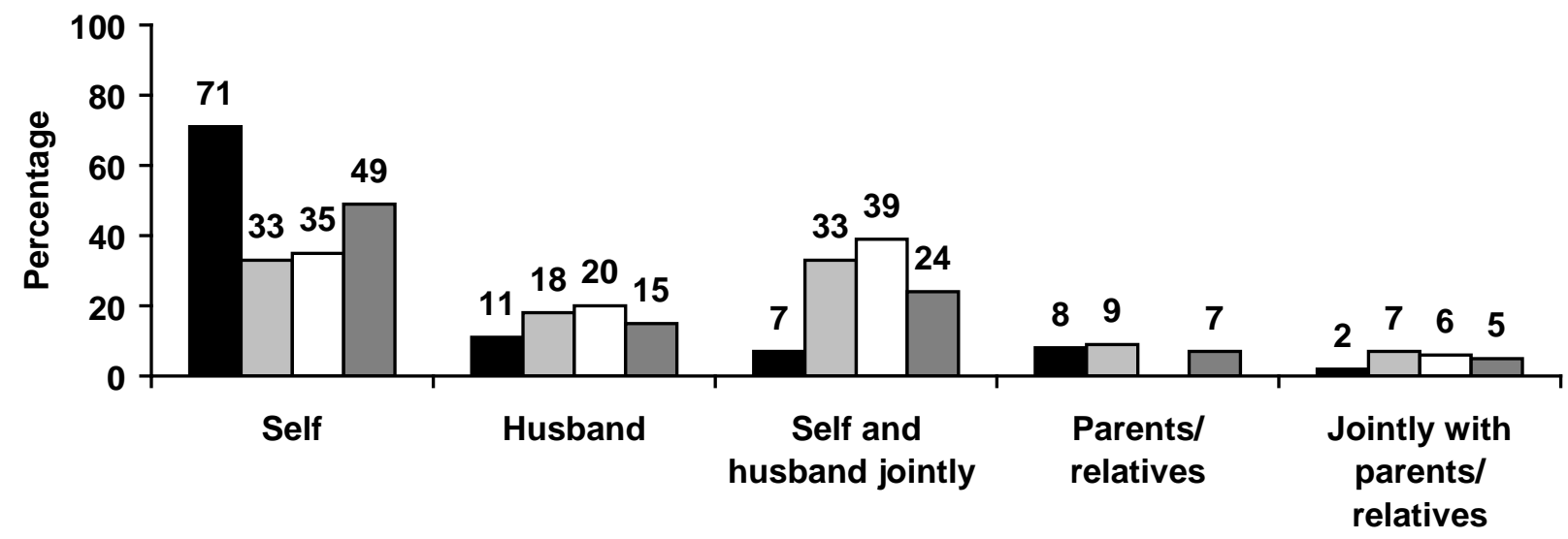

Of the 131 women who were informed first of their test result, 92 percent reported they had disclosed their status to one or more family members. Most mentioned they told their husband, followed by their mother, sibling, father, and parent-in-law. Among the 239 currently married women, 42 percent of 


\section{Hgrizons}

women mentioned that their husband knew their status as a result of disclosure by the provider or through joint counseling. Of the 138 women who mentioned they or their parents/relatives were informed first, 22 percent $(n=30)$ did not disclose their status to their husbands. Of these, 10 women had an HIV-positive husband, three had an HIV-negative husband and the rest $(n=17)$ did not know their husband's status. When these women were further asked about the reason for not disclosing their status to their husband, most expressed fear of being abandoned.

If I tell my HIV status, he will leave me and my children. He will get married again. I am afraid of that.

HIV-positive pregnant woman

Ours is love marriage [marriage by own choice as opposed to marriage arranged by family]. If I tell him [my status] he will have doubt on me. He is the only person looking after me. If I tell him he will surely leave me and go. So I do not want to tell him. I will become helpless.

HIV-positive postpartum woman

The respondents who reported disclosing their status were asked if they felt they should not have done so. The majority of the women did not regret their decision to share their status with someone else.

I had to get the support. Also I needed to share this with someone close.

HIV-positive pregnant woman

I did not want to hide; rather I was wanting to tell.

HIV-positive postpartum woman

No, I never felt I should not have done so [told my status].

HIV-positive pregnant woman

There were some women who felt otherwise and shared their negative experiences of being stigmatized and discriminated against by family members.

Yes, I feel bad having told. When there is some quarrel, my mother will say you are loose character woman, go and die somewhere. Why are you troubling us.

HIV-positive pregnant woman

I regret sharing my status with my in-laws. Instead of supporting me their attitude is bad towards me.

HIV-positive pregnant woman

After sharing my status with my husband, he beats me and blames me for giving him the disease.

HIV-positive post partum woman

My mother told me to keep all my things separate like soap, towel, brush, etc. She asked me not to hug and kiss my child. She also kept my plates and glass separate.

HIV-positive post partum woman 


\section{PPTCT Experiences}

\section{Antenatal care and delivery}

Of the 268 women surveyed, 97 were pregnant at the time of the interview and 171 had a delivery in the past 24 months. Among the pregnant women, over half were in the last trimester of pregnancy with an average gestation of 7 months. About half (48 percent) of the 171 postpartum women had a delivery less than six months ago and about a third had a delivery between 6 and 12 months ago. The mean number of months postpartum was 9.2 months. The majority of women in Bangalore and Hyderabad were between 1 and 6 months postpartum while in Imphal, the majority of women were late postpartum (19-24 months).

All of the currently pregnant women surveyed were attending an antenatal clinic for care. Close to half of the pregnant women reported they started ANC in their first trimester, half during their second trimester, and about 14 percent during their third trimester. Depending on the months of gestation, a third of the women reported making 2-3 visits and another third reported making more than six visits to the ANC center.

Yes, I have visited them thrice. I got myself registered when I was four months [pregnant] during that time. I don't have any problem in getting there as I have been there during my first pregnancy also. They told me to come once every month which I have been doing.

HIV-positive pregnant woman

The majority of the pregnant women reported they wanted to give birth to their child at the same health facility where they were receiving their ANC services, primarily because these facilities knew about their status and were providing care to them.

I want to deliver in this hospital because being HIV-positive all my check-ups are done here. So I want to deliver here only.

HIV-positive pregnant woman

I want to deliver here only because in no other hospital they are giving care and conducting delivery for HIV-positives. This being a government hospital everything for HIV-positive people is free over here.

HIV-positive pregnant woman

When postpartum women were asked about the number of times they accessed ANC during their most recent pregnancy, 47 percent said six or more than six visits, 45 percent said $2-5$ visits, 7 percent said one visit, and only 1 percent said no visit.

When asked about their last delivery, 65 percent of postpartum women had a normal/vaginal delivery, 6 percent had a vaginal delivery with episiotomy, 28 percent had a cesarean operation, and 2 percent had a medical termination of pregnancy (MTP) or a medical abortion during their pregnancy (they were also included in the study sample as they continued to participate in the NGO's activities for PPTCT clients). In Hyderabad, over half of the women reported they had undergone a cesarean operation during delivery (see Figure 5). 
Figure 5 Type of delivery reported by postpartum women by city

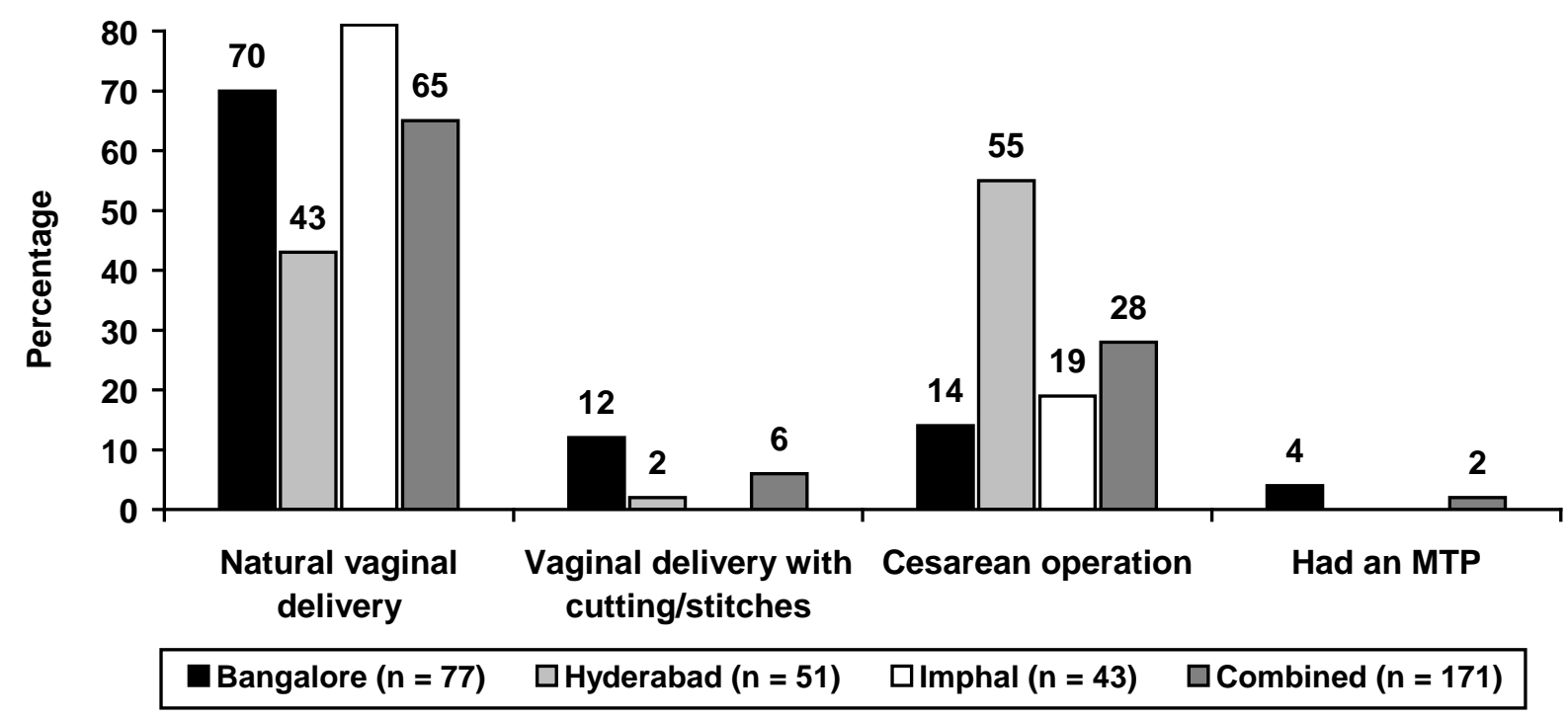

Three-fourths $(n=127)$ of post-partum women had their delivery in the same hospital they received ANC or PPTCT services, 22 percent went to another hospital for delivery, and 2 percent delivered at home. Among the women who had a delivery in the same sites where they received ANC or PPTCT services (n = 127), the majority of women who had a cesarean delivered their baby in a private hospital (see Table 6).

Table 6 Type of delivery reported by postpartum women who delivered in the same hospital where they received ANC or PPTCT services

\begin{tabular}{lcccc}
\hline Type of delivery & $\begin{array}{c}\text { Public sector } \\
\text { with PPTCT } \\
\text { program } \\
(\mathbf{n}=\mathbf{4 4 )} \\
\mathbf{\%}\end{array}$ & $\begin{array}{c}\text { EGPAF- } \\
\text { supported } \\
\text { public sector } \\
(\mathbf{n}=\mathbf{6 0}) \\
\mathbf{\%}\end{array}$ & $\begin{array}{c}\text { EGPAF- } \\
\text { supported } \\
\text { private sector } \\
(\mathbf{n}=\mathbf{2 3}) \\
\mathbf{\%}\end{array}$ & $\begin{array}{c}\text { Combined } \\
\text { sites } \\
(\mathbf{n}=\mathbf{1 2 7}) \\
\mathbf{\%}\end{array}$ \\
\hline Natural delivery (vaginal delivery) & 80 & 77 & 30 & 69 \\
$\begin{array}{l}\text { Vaginal with cutting/stitches } \\
\text { (episiotomy) }\end{array}$ & - & 8 & - & 4 \\
Cesarean section (operation) & 20 & 15 & 70 & 27 \\
\hline
\end{tabular}

Forty percent of women who had a cesarean section delivery did so based on their doctor/counselor's advice. Close to a third said it was due to complications and another fourth said to reduce the risk of HIV transmission to their child. The qualitative interviews support these reasons. 
I had a cesarean section delivery at government hospital. Initially the doctor tried for normal delivery option but due to some complication they had to do the operation.

HIV-positive postpartum woman

I underwent cesarean, as the percentage of transmission will be less by cesarean delivery, only 25 percent comes. OK no problem even if money was spent, child should survive and the mother should be good, that's what my husband thought and got it done.

HIV-positive postpartum woman

\section{Antiretroviral Prophylaxis for Reducing Vertical Transmission}

As per the national PPTCT guidelines, in all government hospitals HIV-positive pregnant women are provided Nevirapine (NVP) as ARV prophylaxis. It is administered to pregnant HIV-positive women at the onset of labor. The newborn infant is also provided a single dose of NVP within 72 hours of delivery. The EGPAF-funded NGO PPTCT Program provided women an option of medications that included Zidovudine/AZT (starting as early as 14 weeks of pregnancy and no later than 36 weeks of pregnancy) as well as NVP during labor.

Almost all the women reported that their ANC provider informed them of medication they can take to reduce the risk of HIV transmission to their child during pregnancy, delivery, and infant feeding. About a fourth of pregnant women (97) were currently taking medicine to reduce the risk of HIV transmission to their unborn child; most were taking AZT and only a small percentage (3) were on ART.

Of the women on AZT ( $\mathrm{n}=27$ ), 9 started between 14 and 27 weeks of pregnancy, 15 started between 28 and 32 weeks of pregnancy, and 3 started after 36 weeks of pregnancy. All women who reported taking AZT were receiving PPTCT services from private and public sector hospitals where the EGPAFsupported NGO program was being implemented. According to the counselors in the EGPAF-supported PPTCT sites, they counsel women about the types of medications and dosages, and depending on their ability to adhere to and comply with the dosages required, the women are provided the most appropriate medication. (For further details about the medications, see Appendix 1.)

The main reasons why pregnant women not on medication were not taking them was that they were still in the early stage of pregnancy or they wanted to take NVP at delivery. Most of the women who said they would take NVP were from the public sector sites (including those supported by EGPAF).

The majority of postpartum women who had a delivery mentioned they took medicine to reduce the risk of HIV transmission to their child: 62 percent took Nevirapine and 21 percent mentioned AZT, which they started taking between weeks 14 to 36 of pregnancy. Only one woman mentioned that she was on ART during her pregnancy. Nine percent did not take any medicine (see Table 7). The majority of women who did not take the medicine were from the EGPAF-supported public sector site. Most of the women who did not take any medicine said it was because they had their delivery at home and came to the health facility only after delivery. In most of these cases, the women reported that their infant had received the medication. 
Table 7 Type of medication currently taking or ever taken by HIV-positive women

\begin{tabular}{lcccc}
\hline & $\begin{array}{c}\text { Public } \\
\text { sector } \\
\%\end{array}$ & $\begin{array}{c}\text { EGPAF- } \\
\text { supported } \\
\text { public sector } \\
\%\end{array}$ & $\begin{array}{c}\text { EGPAF- } \\
\text { supported } \\
\text { private sector } \\
\%\end{array}$ & $\begin{array}{c}\text { Combined } \\
\text { sites } \\
\%\end{array}$ \\
\hline Pregnant women (currently taking) & $\mathrm{n}=35$ & $\mathrm{n}=40$ & $\mathrm{n}=22$ & $\mathrm{n}=97$ \\
$\quad$ AZT (Zidovudine) & - & 20 & 86 & 28 \\
Antiretroviral therapy (ART) & 8 & - & - & 3 \\
Not taking any medicine currently & 92 & 80 & 14 & 69 \\
\hline Postpartum women (who had a & $\mathrm{n}=49$ & $\mathrm{n}=91$ & $\mathrm{n}=28$ & $\mathrm{n}=168$ \\
delivery) & & & & \\
\hline Nevirapine only (during labor) & 84 & 62 & 26 & 62 \\
AZT + NVP (pregnancy and labor) & - & 19 & 64 & 21 \\
On ART & - & 1 & - & 1 \\
Do not remember & 12 & 4 & 3 & 7 \\
Did not take & 4 & 14 & 7 & 9 \\
\hline
\end{tabular}

Among all the postpartum women who had a live birth $(n=164), 86$ percent said their baby received/was provided medication (see Table 8). Only 5 percent reported their infant did not receive the medication and 9 percent said they did not remember. Overall, the majority (58 percent) of women mentioned their infant received NVP and a fourth said their infant was given multiple doses of AZT (for one week). This latter group of women had received PPTCT services from the EGPAF-supported program in the public and private sector hospitals in Bangalore and Hyderabad, where the prophylaxis for infants differed from that provided under the national program (see Appendix 1).

Table 8 Type of medicine given to child after birth reported by postpartum women who had a live birth

\begin{tabular}{lcccc}
\hline $\begin{array}{l}\text { Type of medication given to } \\
\text { child after delivery }\end{array}$ & $\begin{array}{c}\text { Public sector } \\
(\mathbf{n}=\mathbf{4 8}) \\
\%\end{array}$ & $\begin{array}{c}\text { EGPAF- } \\
\text { supported } \\
\text { public sector } \\
(\mathbf{n}=\mathbf{8 9}) \\
\mathbf{\%}\end{array}$ & $\begin{array}{c}\text { EGPAF- } \\
\text { supported } \\
\text { private sector } \\
(\mathbf{n}=\mathbf{2 7}) \\
\%\end{array}$ & $\begin{array}{c}\text { Combined sites } \\
(\mathbf{n}=\mathbf{1 6 4}) \\
\%\end{array}$ \\
\hline $\begin{array}{l}\text { Nevirapine (single dose within } 72 \\
\text { hours of birth) }\end{array}$ & 85 & 52 & 33 & 58 \\
AZT (multiple dose for 1 week) & - & 32 & 63 & 28 \\
Do not remember & 13 & 8 & - & 9 \\
Did not get any medication & 2 & 8 & 4 & 5 \\
\hline
\end{tabular}




\section{Infant Feeding Counseling and Practices}

Among the postpartum women with live births $(n=164 / 171)$ three-fourths opted for replacement feeding for their child, a fifth chose exclusive breastfeeding, and 7 percent opted for mixed feeding (breastfeeding and replacement feeding together) (see Figure 6).

Figure 6 Infant feeding options chosen by postpartum women with living children $(n=164)$

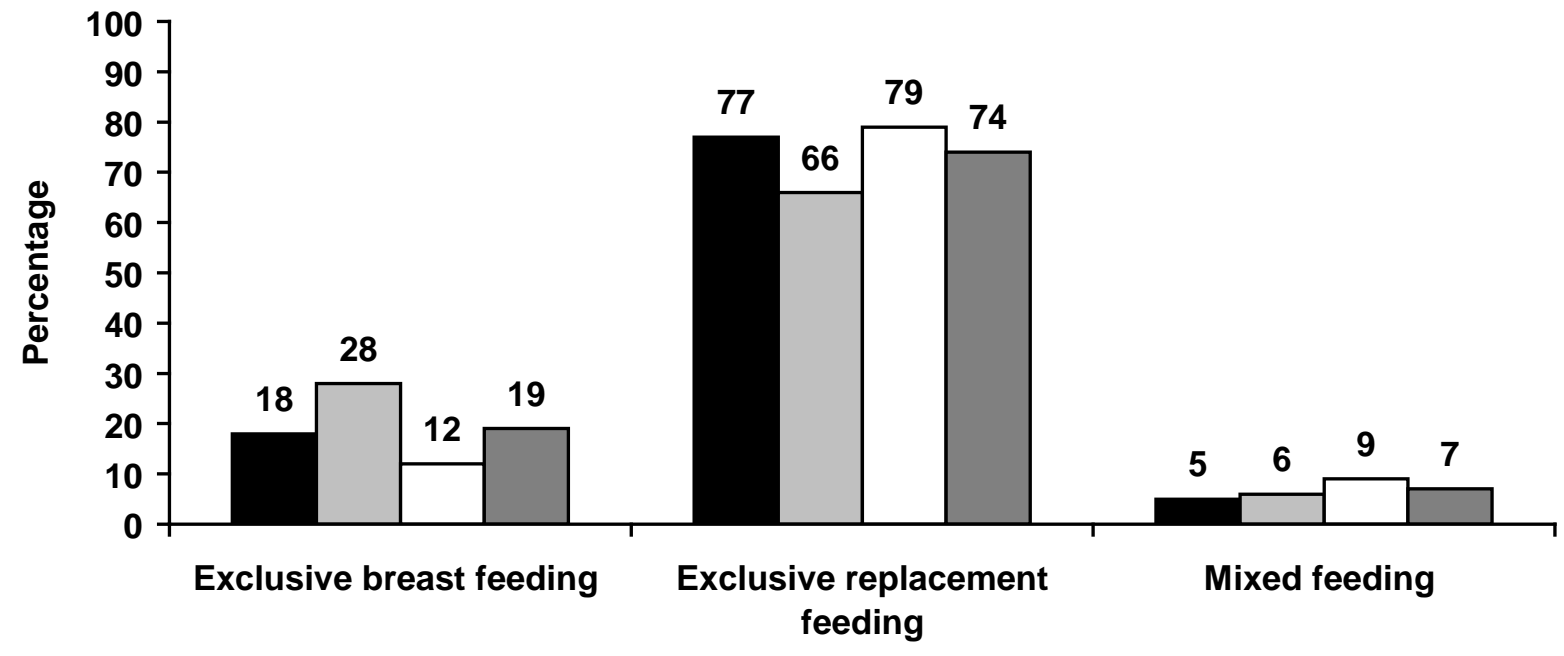

Bangalore $\quad \square$ Hyderabad $\square$ Imphal $\square$ Combined

Table 9 shows that women who received services from the public sector and EGPAF-supported private sector sites were more likely to exclusively use replacement feeding compared to women from the EGPAF-supported public sector sites. When the women who opted for replacement feeding were asked the reason for their choice, the most common reason was to prevent HIV transmission to their child.

Table 9 Type of infant feeding chosen by postpartum women

\begin{tabular}{lcccc}
\hline & $\begin{array}{c}\text { Public sector } \\
(\mathbf{n = 4 8 )} \\
\%\end{array}$ & $\begin{array}{c}\text { EGPAF- } \\
\text { supported } \\
\text { public sector } \\
(\mathbf{n = 8 9 )} \\
\mathbf{\%}\end{array}$ & $\begin{array}{c}\text { EGPAF- } \\
\text { supported } \\
\text { private sector } \\
(\mathbf{n}=\mathbf{2 7}) \\
\mathbf{\%}\end{array}$ & $\begin{array}{c}\text { Combined sites } \\
(\mathbf{n}=\mathbf{1 6 4})\end{array}$ \\
\hline Exclusive breastfeeding & 14 & 26 & 11 & $\%$ \\
Exclusive replacement feeding & 82 & 66 & 89 & 20 \\
Mixed feeding & 4 & 8 & - & 75 \\
\hline
\end{tabular}




\section{Hgrizons}

Most women who opted for exclusive breastfeeding believed that this method was the best for their child's health. The second most common reason was that they did not have enough money to provide replacement feeding, followed by "family advised to choose breastfeeding," because they feared being stigmatized by others for not being able to breastfeed their own infant.

The counselor told me that you can give breast milk to your baby till three months. But she also told me that if you give mother's milk there is a chance of the child getting it. She told me that I can also use powder milk. But she told me it is expensive. From where can we spend so much money? And, everybody will come and ask why I am not giving my milk. My mother-in-law also will not keep quiet. So I told her I will give my own milk.

HIV-positive postpartum woman

I have been told by counselor to give top feed for the baby but since I cannot afford to buy milk I started giving breast milk. Still feeding my child though the counselor has asked me to stop my feed.

HIV-positive postpartum woman

Thirteen of the 22 women currently breastfeeding their infant mentioned they planned to continue to breastfeed their child until three months of age, six mentioned until the child is six months, and three reported until the child is 8-18 months old. Of the women who had breastfed their child but were not currently breastfeeding $(\mathrm{n}=19)$, nine breastfed until the child was three months, three until six months, five till the child was less than a year, and the remaining two till 24 months.

Weaning practices were explored only among those who had breastfed their child. Eight of these women mentioned they suddenly stopped breastfeeding and gave weaning foods to their child, while 11 mentioned they gradually weaned their child off of breast milk. In qualitative interviews, women provided details about their weaning practices. The interviews also revealed that the period of weaning varied from 6-12 months and also resulted in mixed feeding practices.

I breastfed my baby. But from the $4^{\text {th }}$ month onwards I started feeding her boiled rice in the day time but in the night time I used to breastfeed. I completely stopped when she was 7 or 8 months old. I stopped because no more milk was coming out.

HIV-positive postpartum woman

The majority of the women who opted for replacement feeding mentioned that they felt sad and depressed for choosing not to breastfeed their child, which was understandable in light of the cultural context which places a premium on breastfeeding and "mother's milk." But, when they thought about the risk of transmitting HIV to their infant through breast milk they opted for replacement feeding.

I really cried so much. I cannot tell you. That moment I can never forget in my life time. Which woman will personally stop her milk and give top feed (replacement feed). It is against humanity. But I thought since I am HIV-positive I do not want my infection should go to my child. So I decided to give top feed.

HIV-positive postpartum woman 
When I look at all the mothers who are feeding breast milk I feel sad for my child. But my child should be healthy. So I controlled myself and my child should not get any disease.

HIV-positive postpartum woman

I felt a bit guilty as I could not give my own breast milk being a mother.

HIV-positive postpartum woman

Many of them also reported that they had to face questions from their family members and relatives about the reason for not giving breast milk to their infant. Most of the women said they usually lied about their condition when answering the questions.

I am suffering a lot. People are constantly questioning me why I am not breastfeeding the child. It is a torture to me.

HIV-positive postpartum woman

Many people asked me why you are not giving your milk. For some I told I do not have milk and for some I am very weak and for some doctor has told not to give. More than that I felt bad for not feeding my child.

HIV-positive postpartum woman

After my delivery I went to my village. I felt too sad that I could not feed my child. All were asking why you are not feeding your child? I told them lie that I do not have the milk. I cried like anything after that.

HIV-positive postpartum woman

Some women reported changing from their earlier chosen method of infant feeding to breastfeeding due to family pressure or fear of being stigmatized for not breastfeeding. This would often result in the women following mixed-feeding practices.

My husband insisted on exclusive bottle feeding the child. Initially I used to but the four sisters-inlaw scolded me endlessly on the ground that I was doing it to preserve my figure for fashion etc. Ultimately, I had to breastfeed my baby [as I was] not able to bear their attitudes, as we are dependent on them financially. I am still breastfeeding and will continue doing so till she starts eating. Though my husband and I agreed to do bottle feeding we had to stop as we both are afraid of confronting his sisters. It makes us so guilty knowing the risk to the child.

HIV-positive postpartum woman

I was earlier giving lactogen [powder milk]. Now, I have started to breastfeed my baby because of my in-laws and husband. But I have fear what will happen to my child? This has become daily thought for me. Even if a small problem happens to my baby, I worry too much. Only my husband knows I am HIV-positive, not his relatives. If I do not breastfeed they will have doubt so I am breastfeeding my child for the last two months.

HIV-positive postpartum woman

Half of the women who chose replacement and mixed feeding gave formula feed. 


\section{Hgrizons}

I feed her with Nestogen [formula feed]. I have more than 4 bottles. I boil the bottles and clean it. I put the powder in the bottle and mix it with boiled water. I shake the bottle till it cools down and then only give it to my daughter.

HIV-positive postpartum woman

Another 37 percent gave their baby pasteurized packet milk, and 12 percent gave animal milk. The vast majority (85 percent) were told or shown how to prepare replacement feed for their child. But 15 percent did not receive any advice on this at all. Of the 123 women who opted for replacement feeding, 76 percent said they received a medication to stop production of breast milk, while 20 percent said they did not receive it and 4 percent said they did not know if they received it.

About half of the women mentioned that the infant feeding method decision was made jointly by them and their husbands, a third decided on their own, 5 percent said the service provider influenced the decision, 4 percent said the husband alone, and the rest said it was the family's decision. In qualitative interviews, while most of the women who opted for replacement feeding mentioned it was their decision they also talked about the influence of the service provider in arriving at this decision.

Even before my delivery, Dr.... told me not to breastfed the baby but to do "top feeding" [replacement feeding].

HIV-positive postpartum woman

I did not feed my milk but gave formula milk, lactogen, for six months. The doctor had told me that, "why do you want to feed your milk and infect your disease to the baby?"

HIV-postpartum woman

In this NGO, when we came, they gave information about giving milk to the baby. If a mother who has HIV gives her milk to the baby, the baby could get the infection. Then we thought and decided, it is good to give top feed for the baby. From the beginning, we are giving lactogen.

HIV-positive postpartum woman

When asked if their child suffered any health problems since starting on replacement feed, 90 percent mentioned no health problems. But the remaining 10 percent reported that their child suffered from weakness, diarrhea, vomiting, and fever. In qualitative interviews, women provided more details of their child's ill-health due to replacement feeding.

I was told to give formula [lactogen] to my baby. I was told to first boil everything nicely in water and then give, so I did and got in trouble as the child got loose motions. There was a clinic near my mother's house and I showed there. The doctor treated the child and told me, "don't give this milk give soybean milk." I started giving soya milk to my child. But with this also the child got loose motions. How much ever medicines were given but still the motions did not stop. The child started losing weight day by day then we had to take him to the hospital. Now I am giving pasteurized milk. When I told the doctor that my child finds difficult to pass motion then they told give boiled water to the child to drink. Two spoons of water. Past 10 days I am giving pasteurized milk there is no trouble now and I shall continue the same.

HIV-postpartum woman 


\section{HIV Treatment, Care, and Support}

A basic tenet of PPTCT programs is to provide ongoing care to HIV-positive women and their families. Thus, the study examined whether PPTCT programs offered women an opportunity to access existing HIV care and support services. In addition, the researchers explored women's awareness and access to ART, given the wider availability of ART in India as a result of the national ARV treatment program (including in the study's three cities and through some of the study hospitals).

\section{Awareness of and access to HIV treatment}

Overall, only 41 percent of the women reported they had ever heard of treatment for HIV or ART. When the data were disaggregated by city, most of the women who were aware of ARV treatment were from Imphal (see Figure 7). This may be due to a variety of reasons. One could be that that most of the women recruited for the study in Imphal were linked to a care and support NGO and not just to the PPTCT program. Also, the women in Imphal were diagnosed HIV-positive earlier than the women from the other two cities and may have been informed about ART by the NGO based on their health condition.

\section{Figure 7 Awareness of ART}

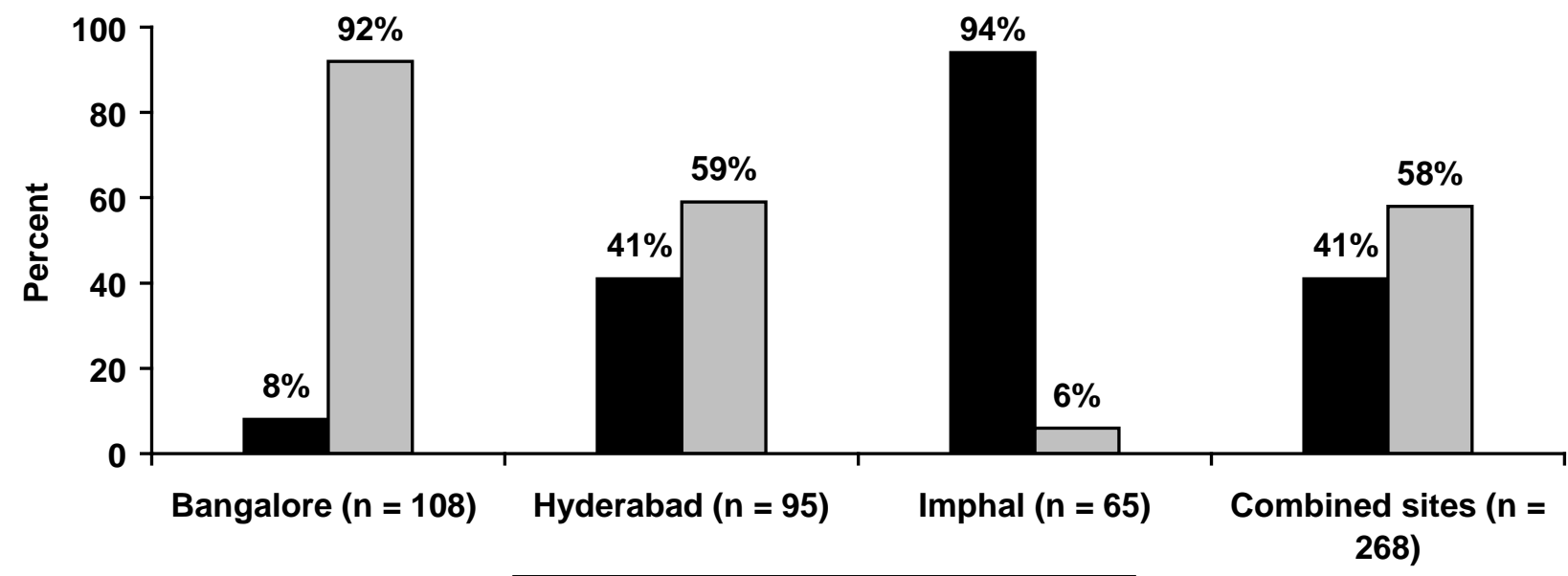

Heard of ART $\square$ Not heard of ART

During antenatal care, less than a third (30 percent) of the respondents reported they were informed about CD4 testing to determine not only their cell count but also to assess their eligibility for starting ARV treatment, and only 18 percent were informed about ARV treatment by their provider (see Table 10). 


\section{Hgrizons}

Table 10 Information on HIV treatment received during ANC

\begin{tabular}{lcccc}
\hline & $\begin{array}{c}\text { Bangalore } \\
(\mathbf{n = 1 0 8}) \\
\%\end{array}$ & $\begin{array}{c}\text { Hyderabad } \\
(\mathbf{n = 9 5 )} \\
\%\end{array}$ & $\begin{array}{c}\text { Imphal } \\
(\mathbf{n}=\mathbf{6 5}) \\
\%\end{array}$ & $\begin{array}{c}\text { Total } \\
(\mathbf{n}=\mathbf{2 6 8}) \\
\%\end{array}$ \\
\hline Informed about ARV treatment & 6 & 13 & 46 & 18 \\
Informed about CD4 testing & 10 & 36 & 54 & 30 \\
\hline
\end{tabular}

Seven percent $(n=19)$ of the study sample was currently on ART. Fifteen of the women started treatment less than a year ago and the others started between 1 and 2 years ago. Of the 19 women on ART, 16 were from Imphal, two from Bangalore, and one from Hyderabad. Most of the women receiving ARV were diagnosed as HIV-positive over two years ago.

Yes, I am on ART for the past two years. I had TB and because I was very ill. I also got fits. I had brain tumor also so the doctor told me if you stay like this it will not work you have to take tablets otherwise your health will worsen.

HIV-positive postpartum woman

Only two women mentioned that their PPTCT provider referred them to the ARV facility.

Fourteen women received their ARV medication from the public sector free of charge while four obtained ARVs from an NGO. Only one woman reported that she bought her medication from a chemist. The woman who purchased ARVs from the chemist was from a higher socioeconomic group.

I am getting my medicines from the district hospital because of the NGO's support.

HIV-positive postpartum woman

I get it at NGO Care Home. They give me free, no money is given.

HIV-positive postpartum woman

Among the 176 women with a living husband who was HIV-positive, 28 percent reported that their husbands were receiving ART. Similarly, the majority of the men receiving ART were from Imphal. Almost all the men had started ART prior to their wives. But when asked if the men receiving ART tested HIV-positive prior to their own diagnosis, about a third of the women reported that their husband was diagnosed after they were. A total of 11 couples were receiving ART; half of them received it from the same facility.

\section{HIV testing and treatment for children}

Pediatric HIV testing is one component of the national PPTCT program. Under the program, infants are tested with the HIV ELISA test at 18 months of age. This test is offered in all public hospitals where the PPTCT program is being implemented. Women accessing the PPTCT program through the EGPAF- 
supported public and private hospitals were offered the option of testing their newborns at three months of age with the Polymerase Chain Reaction (PCR) test ${ }^{2}$.

Among the 211 women with living children, 56 percent had one living child and 44 percent had two to five living children. At least one child of more than half ( 55 percent) of these women had been tested for HIV. Fewer women in Imphal reported that all their children had been tested for HIV compared to Bangalore and Hyderabad (see Figure 8). In Bangalore and Hyderabad, a sizeable proportion of women were enrolled in the EGPAF-supported PPTCT program in public and private hospitals that not only provided outreach services and ongoing counseling to women and their families but also offered the PCR test for infants at a much younger age (three months) than when the national program advised women to return with their infants for HIV ELISA testing (18 months). In Imphal, all the women recruited for the study were enrolled in the public sector PPTCT program.

Figure 8 Proportion of women's living children who had been tested for HIV

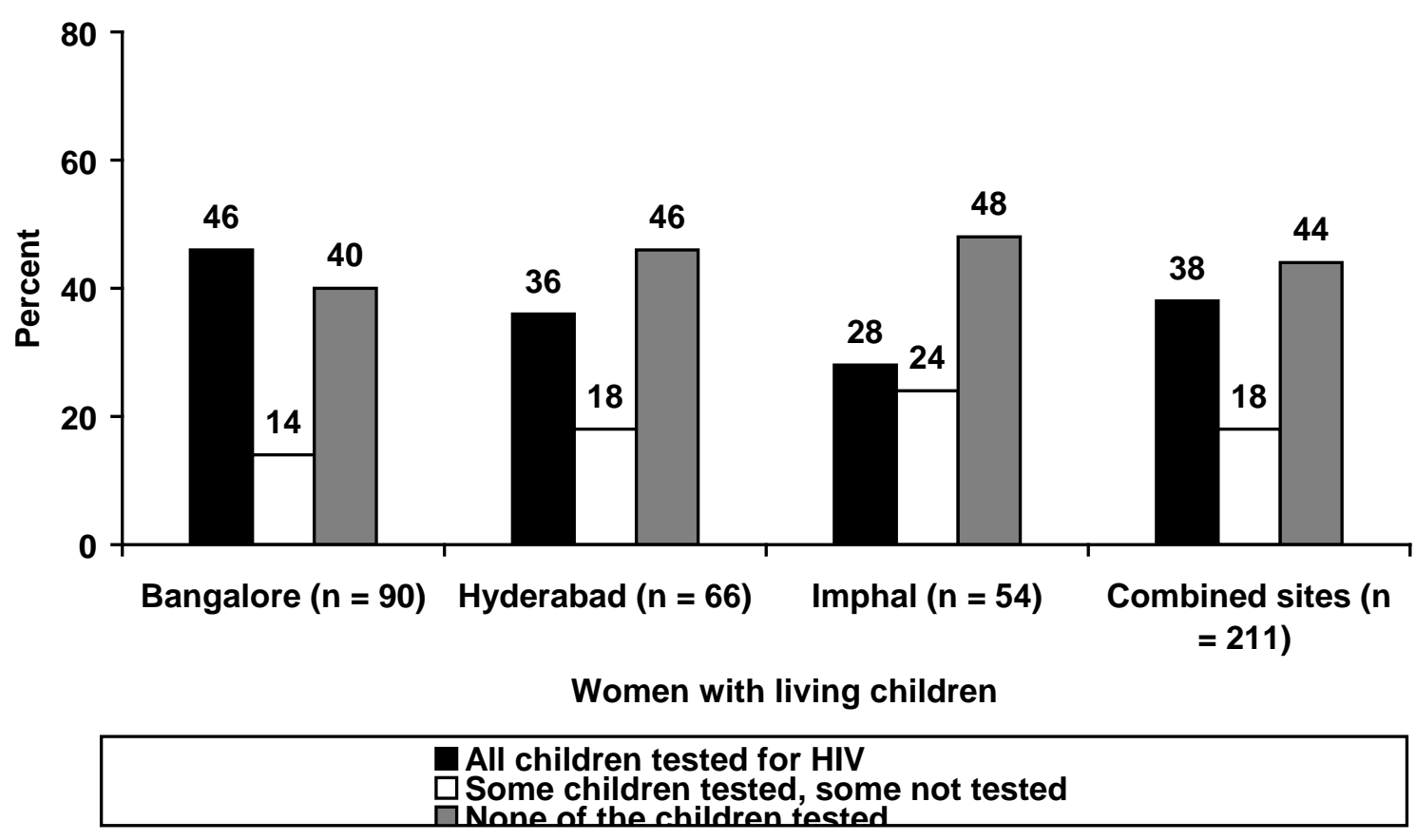

When the data were disaggregated by type of facility, PPTCT clients from the NGO-supported sites were more likely to have had one or more of their children tested compared to women from the public sector (see Table 11). The test was most often recommended by the service provider and was usually done as part of PPTCT services.

\footnotetext{
${ }^{2}$ The PCR (polymerase chain reaction), often detects HIV infection months before the antibody test (HIV ELISA test). For HIV diagnosis, the PCR test is used to detect genetic information inserted into the DNA of human cells by HIV as early as 2-4 weeks after infection.
} 


\section{Hgrizons}

Table 11 Women with living children who had at least one child tested, by type of facility

\begin{tabular}{lcccc}
\hline & $\begin{array}{c}\text { Public sector } \\
(\mathrm{n}=\mathbf{6 9}) \\
\%\end{array}$ & $\begin{array}{c}\text { EGPAF- } \\
\text { supported } \\
\text { public sector } \\
(\mathbf{n}=105) \\
\%\end{array}$ & $\begin{array}{c}\text { EGPAF- } \\
\text { supported } \\
\text { private sector } \\
(\mathbf{n}=\mathbf{3 7}) \\
\%\end{array}$ & $\begin{array}{c}\text { Combined sites } \\
(\mathbf{n}=\mathbf{2 1 1}) \\
\%\end{array}$ \\
\hline $\begin{array}{l}\text { One or more living children } \\
\text { tested for HIV }\end{array}$ & 49 & 55 & 70 & 56 \\
\hline
\end{tabular}

Twenty-one percent of the women who had at least one child tested $(n=117)$ reported that one or more of their children was HIV positive. Of the 196 children of these 117 women, 14 percent tested positive for HIV.

When the 211 women with living children were asked specifically if their youngest and second youngest child had been tested for HIV, 42 percent (89) said yes. Twenty of these 89 women had at least one child test positive and about half of these women were informed about ART for their child. Only two women reported that their child was currently on ARVs. Lack of information about the availability of free medication for children and how to access it was a major reason why women did not access ARVs.

...no one here had given me any information about it [free ARV roll-out in public sector hospitals] and when I started inquiring I was told that all hospital "quota" was complete and there was no empty slot for my daughter. I came to know about all these things very late.

HIV-positive pregnant woman with two daughters

The main reasons why women did not get their youngest and second youngest child tested included, "the child is not old enough," "I don’t want to know the status," and "the child is healthy."

\section{Care and support needs and services}

The majority of women reported they received support from family members (80 percent) and from outside the family (94 percent) such as from NGOs. From the family, women mentioned they received psychosocial and financial support, particularly from husbands and parents. Other family members mentioned by the women included siblings and their husband's parents and siblings. Women whose husbands were HIV-negative also mentioned that their main source of support was their husband.

...my husband, he is the main support.

HIV-positive pregnant woman with HIV-negative husband

I have very good and full support from my husband. Even my mother is very good and cooperates and takes care of me.

HIV-positive postpartum woman with HIV-negative husband

At the same time, some women also mentioned being ill-treated by their family members. 
My brother and sister are harassing me, makes me upset. They keep on telling me "don't touch this, don't use our things." They also keep saying "why you want a child when you yourself will die." I feel very hurt when they say things like this.

HIV-positive pregnant woman

My mother-in-law and sister-in-law don't allow me to touch their things. They tell me to keep all my things separate. My mother-in-law also told us to leave the house but my husband said why should I leave, it is my house as I bought it, so you leave. She became angry and left the house.

HIV-positive pregnant woman

Support from outside the family was mainly provided by NGOs (85 percent) as most of the women recruited for the study were participating in NGO-implemented PPTCT programs in Bangalore and Hyderabad, and care and support programs run by NGOs in Imphal.

...we have been getting a lot of support from NGOs. These people are my family now-the health worker, the counselors.

HIV-positive pregnant woman

...we also get a lot of support from this NGO. Now see, we don't have money to buy tablets like calcium, iron, ragi malt - all these they have given us free. We are very much happy and satisfied with all the supports given to us.

HIV-positive postpartum woman

Counselor madam from NGO support is very very important for me. Counselors have given very good and supportive counseling to me.

HIV-positive postpartum woman

When asked about the kind of support received from outside the family, the most common response was emotional and psychological support followed by medical care, nutritional support, child care, and physical care.

Only 20 percent of respondents were members of a peer group (see Figure 9). Membership in a peer support group was associated with time since HIV diagnosis and city. Of the women who were not members of any support group the large majority were those whose HIV status had been diagnosed less than a year ago as compared to women who knew their status for more than two years (65 percent vs. 13 percent). Close to half of the women from Imphal were members of either a peer support group for HIVpositive women only or a mixed support group of HIV-positive men and women. Their greater participation may not only be due to the fact that they were aware of their status for over two years, but that they were also recruited from NGOs that provide care and support services. At the same time, in Bangalore and Hyderabad, the NGOs that supported the PPTCT services from which the women were enrolled in the study did offer care and support, but the PPTCT services were being provided as part of the NGOs' prevention programming. At the time of this study the NGO-managed PPTCT programs were making efforts to start support group meetings specifically for HIV-positive women. 
Figure 9 Women's enrollment in HIV-positive peer support groups

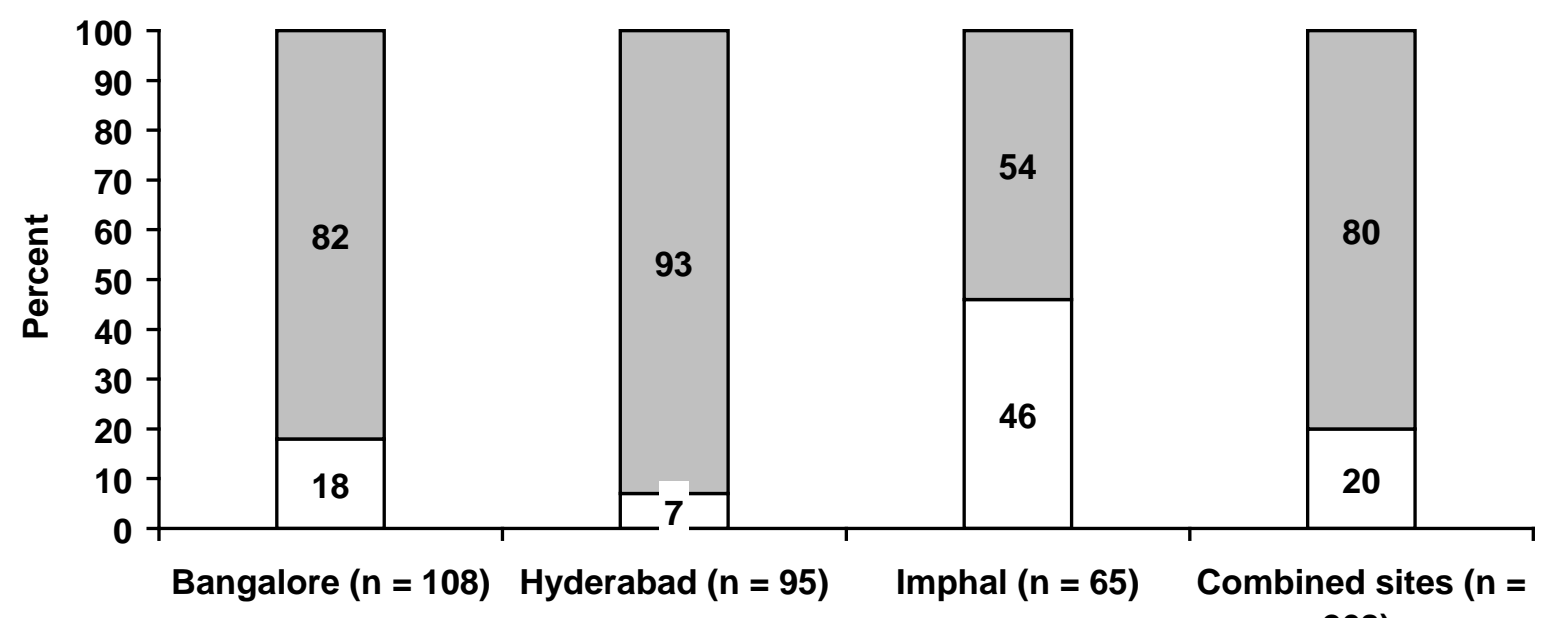

268)

\section{$\square$ No, not a member of a peer group}

$\square$ Yes, member of a peer group

When women who were not members of a peer support group were asked if they would like to join one, over a third (36 percent) said they would, 16 percent were not sure, and close to half (48 percent) said they would not want to join a peer group. Not wanting to join a peer support group was also associated with duration since HIV diagnosis - women who were recently diagnosed were less likely to want to join a peer group. Further probing of survey respondents revealed that women feared that others in their family or community would become aware of their HIV status and they would face stigma and discrimination.

It will not be good if people come to know my status. They may label me as a bad person. I want to lead a secret life till our death.

HIV-positive postpartum woman

I know about these groups, but I am not interested. It will be a problem if everyone comes to know. They will not allow us live and lead our life. So I did not want.

HIV-positive pregnant woman

In qualitative interviews, respondents expressed an interest in joining an HIV-positive mother-to-mother support group rather than an HIV-positive support group. However, most of the women mentioned that they would not want to be a part of a mixed HIV-positive and negative mother-to-mother group.

If the positive and negative mothers are called together it is not good. If there are positive only then they know each others' problems, they can understand better and share their feelings better. But the negative mothers will feel that we are well and free from all these problems which positives are facing. All this will hurt the positive women, so I feel the meetings should be only with the group of HIV-positive mothers. 
If we positive mothers join and do the meetings then there will be unity among us. If negatives join us then they will condemn us that we are positives which we will not like so the group meetings should be between the positives only. We can share our feelings which the others will understand, we will get knowledge from one another.

HIV-positive postpartum woman

They should single us out. If we sit with negative mothers they will not mix with us. They will look down upon us which we will not like. They will not touch us, our children cannot mix and play with the other children because they think they will get the disease from us, so we do not want to have meeting with such people. We would like to be with the positives only who can better understand us and help when needed.

HIV-positive postpartum woman

When women were asked about their plans for care and support for their children, only 39 percent had considered future care options. The majority of these women were from Hyderabad and from the lower socioeconomic categories. Some mentioned that their counselors had encouraged them to think about planning for their children's future. The majority (86 percent) of women who had thought about their children's future said that they would like them to be cared for by their family members and the remaining women said by an NGO.

We will take care of our child till we both die. Our brother-in-law and sister give all kinds of support. Therefore, if something happens to us, we have thought of giving our child to them. Now itself, we have written out a 30x40 foot site in her name. At that time, it will become Rupees 30-40 lakhs (approximately USD10,000). At that time, we will give it to our brother and take his blessings. We have this thought in our mind.

HIV-positive postpartum woman

My mother and grandmother have told not to give the baby to anyone but I am also not interested to give anyone. My mother has promised that she will look after the baby and will support me always.

HIV-positive pregnant woman

\section{Sexual and Reproductive Health}

\section{Unplanned pregnancies, fertility desires, and access to family planning information and services}

More than a third (37 percent) of respondents had one pregnancy, almost half had 2-3 prior pregnancies, and the remainder had 4-8 prior pregnancies (see Table 12). Close to three-fourths of all the women reported that their most recent pregnancy (for postpartum women) or current pregnancy (for pregnant women) was planned, but this varied by site. In Imphal, 46 percent of the women reported that their pregnancy was unplanned, whereas in Bangalore and Hyderabad only 19 percent and 25 percent of women, respectively, reported an unplanned pregnancy. Of the 194 women who had a planned pregnancy, 62 percent were women who did not have a living child prior to the current pregnancy or delivery, 28 percent had 1-2 living children and 10 percent had 3-4 living children. Of the women $(n=74)$ who had an unplanned pregnancy, over three-fourths had more than one living child. Forty percent of all women 


\section{Hgrizons}

reported that after learning their HIV serostatus, they had considered ending their pregnancy. The main reason for wanting to end their pregnancy was the fear of transmitting HIV to their unborn child. Among the women who thought about ending their pregnancy $(n=108), 54$ percent said their pregnancy was planned while 46 percent said it was unplanned.

Table 12 Pregnancy history of HIV-positive pregnant and postpartum women

\begin{tabular}{|c|c|c|c|c|}
\hline & $\begin{array}{c}\text { Bangalore } \\
(n=108) \\
\%\end{array}$ & $\begin{array}{c}\text { Hyderabad } \\
\text { (n = 95) } \\
\%\end{array}$ & $\begin{array}{c}\text { Imphal } \\
(n=65) \\
\%\end{array}$ & $\begin{array}{c}\text { Total } \\
(\mathrm{n}=268) \\
\%\end{array}$ \\
\hline \multicolumn{5}{|c|}{ Number of pregnancies } \\
\hline 1 & 37 & 41 & 29 & 37 \\
\hline $2-3$ & 49 & 52 & 51 & 50 \\
\hline $4-8$ & 14 & 7 & 20 & 13 \\
\hline \multicolumn{5}{|c|}{$\begin{array}{l}\text { Current or most recent } \\
\text { pregnancy planned }\end{array}$} \\
\hline Yes & 82 & 75 & 54 & 72 \\
\hline No & 18 & 25 & 46 & 28 \\
\hline
\end{tabular}

After learning their HIV-positive serostatus, 17 percent of the women had one subsequent pregnancy and 7 percent reported 2-4 subsequent pregnancies (see Figure 10). Women from Imphal had more pregnancies overall (see Table 12) as well as more pregnancies after learning their HIV status compared to women from Bangalore and Hyderabad (see Figure 10). The greater number of pregnancies among women in Imphal may reflect the fact that they had a higher mean age compared to women from Bangalore and Hyderabad.

Figure 10 Number of pregnancies after knowing HIV-positive serostatus

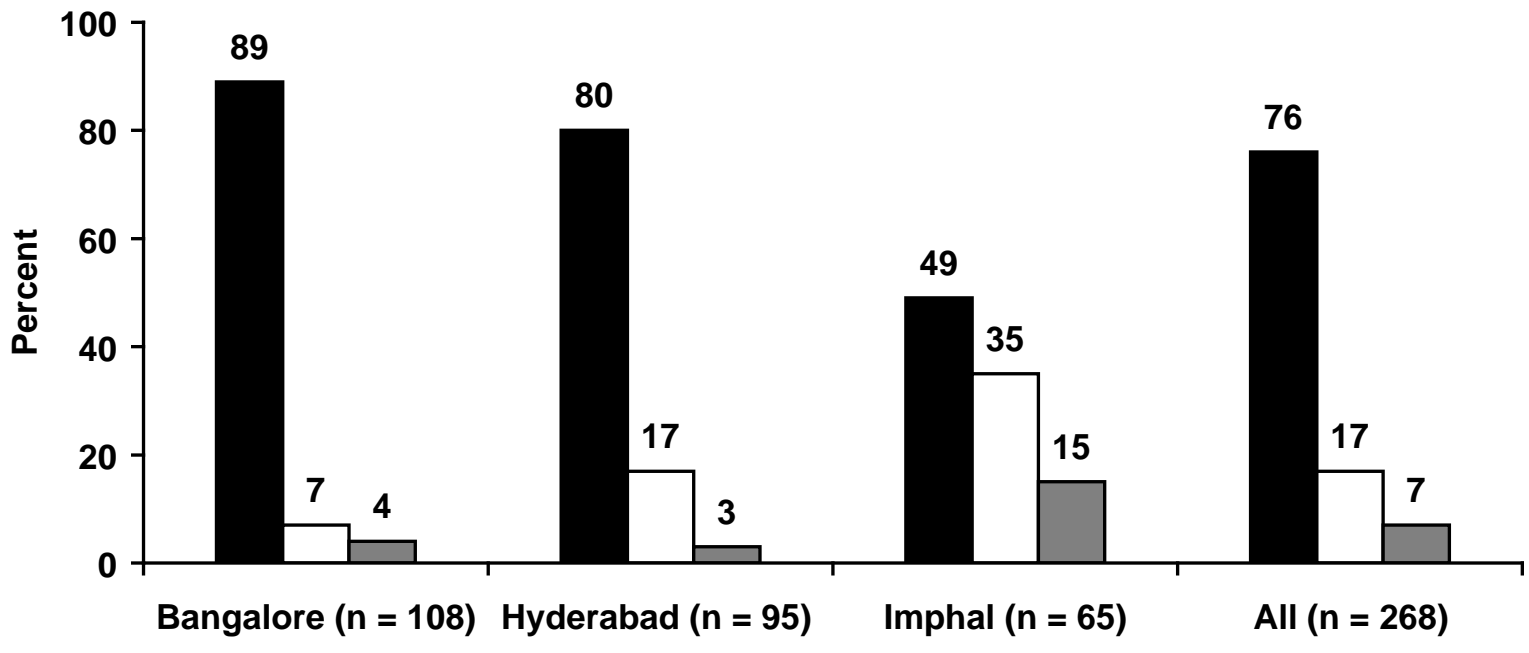

No pregnancy $\square 1$ pregnancy $\quad \square 2$ or more pregnancies 
Among all the women who reported a pregnancy after their HIV status was diagnosed $(n=64), 44$ percent said their recent or current pregnancy was not planned. Moreover, half of the women who had a pregnancy after they knew their HIV-positive serostatus had considered ending their pregnancy. This included both women who reported they had a planned as well as an unplanned pregnancy. The main reason for wanting to end their pregnancy was because they did not want to transmit HIV to their child.

My present pregnancy is unplanned. My first daughter is positive and the second one is always sick. I am afraid she may also be positive. If I carry on this pregnancy, I might end up giving birth to another HIV-positive child. I can't bear any more. So, I am planning to end this pregnancy soon. HIV-positive pregnant woman

I am just two months pregnant. I want to abort this child but I don't have the required amount. Can the NGO pay for my abortion, I want to abort it.

HIV-positive pregnant woman

One of the respondents, a current drug user, shared her experiences of going through with an unplanned pregnancy and her fertility intentions.

My last pregnancy was unplanned. My monthly periods are irregular and many times I don't get it. So I didn't know I was pregnant for a long time. After I came to know I wanted to abort it and my husband also didn't want the child. But somehow I couldn't do because I didn't have the money, didn't know whom to contact, where to go, etc. I was busy all the time and days just passed by. Now I don't want any more children. I don't get my periods at all now.

HIV-positive postpartum woman

Women were also asked if they had undergone an MTP procedure or an induced medical abortion to end their pregnancy after they learned their HIV status. Of the 261 women who were diagnosed HIV-positive before their pregnancy $(n=64)$ and during their pregnancy $(n=197), 8$ percent had undergone an abortion. Analysis of the data for the 64 women who became pregnant after learning their HIV status indicates that 20 percent had undergone an abortion to end their pregnancy, and among these, most had at least one or more living children.

Both pregnant and postpartum women were asked if they wanted to have more children after their current or last pregnancy. The vast majority (87 percent) of women did not want to have more children (see Figure 11). Most of the women who wanted to have another child had either one living child or no children as yet. 


\section{Hgrizons}

\section{Figure 11 Fertility desires of HIV-positive pregnant and postpartum women}

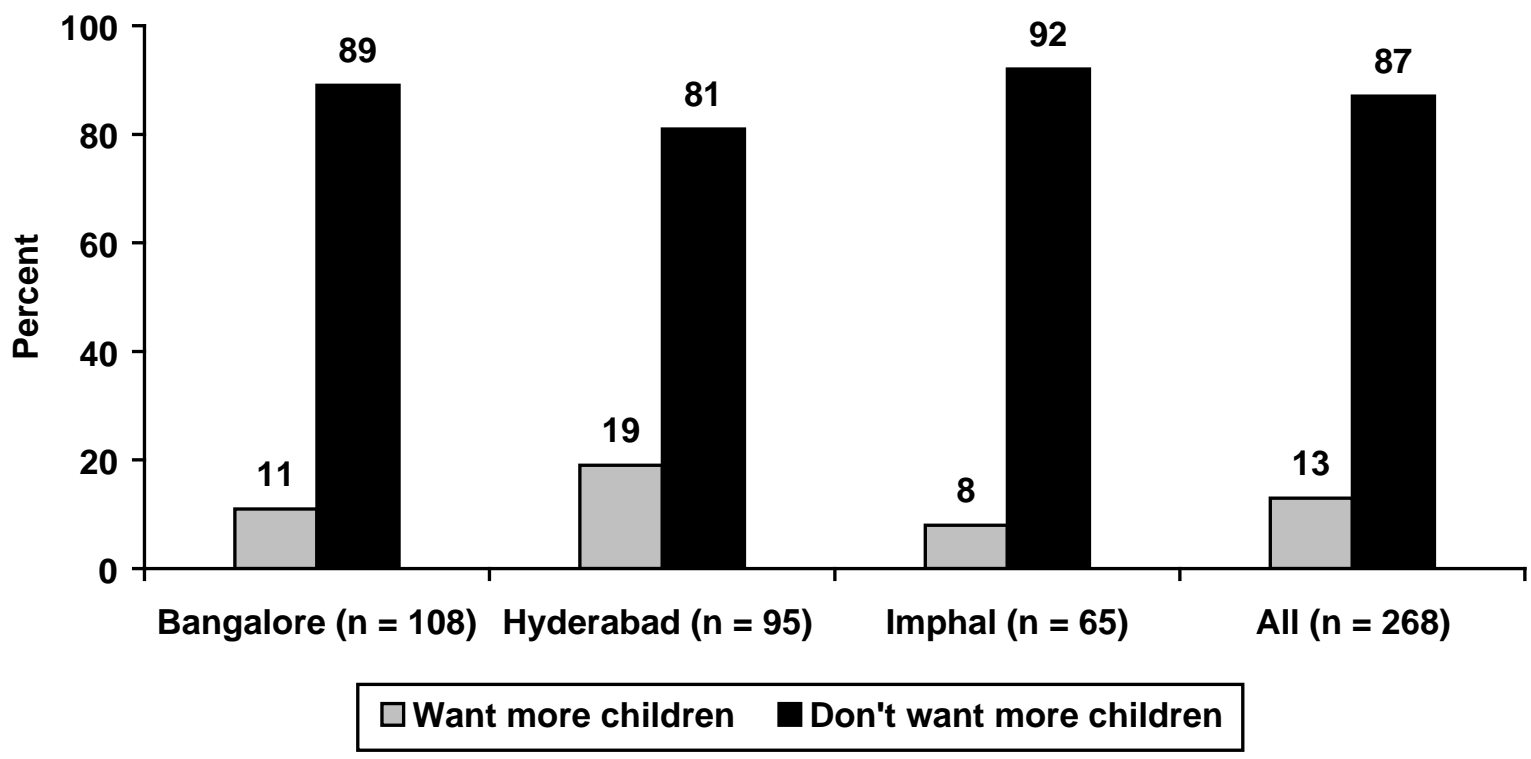

For most of the women who did not want another child, the main reason was concern about the child's future without them. According to one HIV-positive postpartum woman, "I don't want more children ....if something happens to me who will look after my children." However, for some of the women, even if they did not want to have more children their husbands felt otherwise and pressured them to have more children.

...even now [after knowing my HIV status] he wants a child. He says now it is nearly 1 year we shall have one more child. He is very fond of children. It is I who is trying to avoid, I know it is difficult to bring up the child what for men they will not know what we undergo. Knowing the child is positive still he wants a child and I already have 3 children. The counselor had suggested that I go for an operation but my husband said if you get operated don't come home. In the beginning we used Nirodh (condom) but now we have none left. I am daily praying to God I don't want any more children for if I die who will look after them.

HIV-positive postpartum woman

I am going to die so why do I want more children. This child also I am having because my family [husband and mother] forced me to.

HIV-positive pregnant woman

Only 60 percent of postpartum women who did not want to have more children $(n=149)$ reported using any family planning method (see Figure 12). The most common method of family planning was condoms. When the women who were using condoms were asked where they received them, only a third mentioned their PPTCT service provider. Most of the women who had undergone sterilization were advised to do so by a PPTCT provider. 
The counselor explained about family planning. She advised me to get operated after this delivery as I told before I don't want more children. I will go for tubectomy [sterilization] operation.

HIV-positive postpartum woman

Figure 12 Family planning methods used by postpartum women who do not want more children $(n=149)$

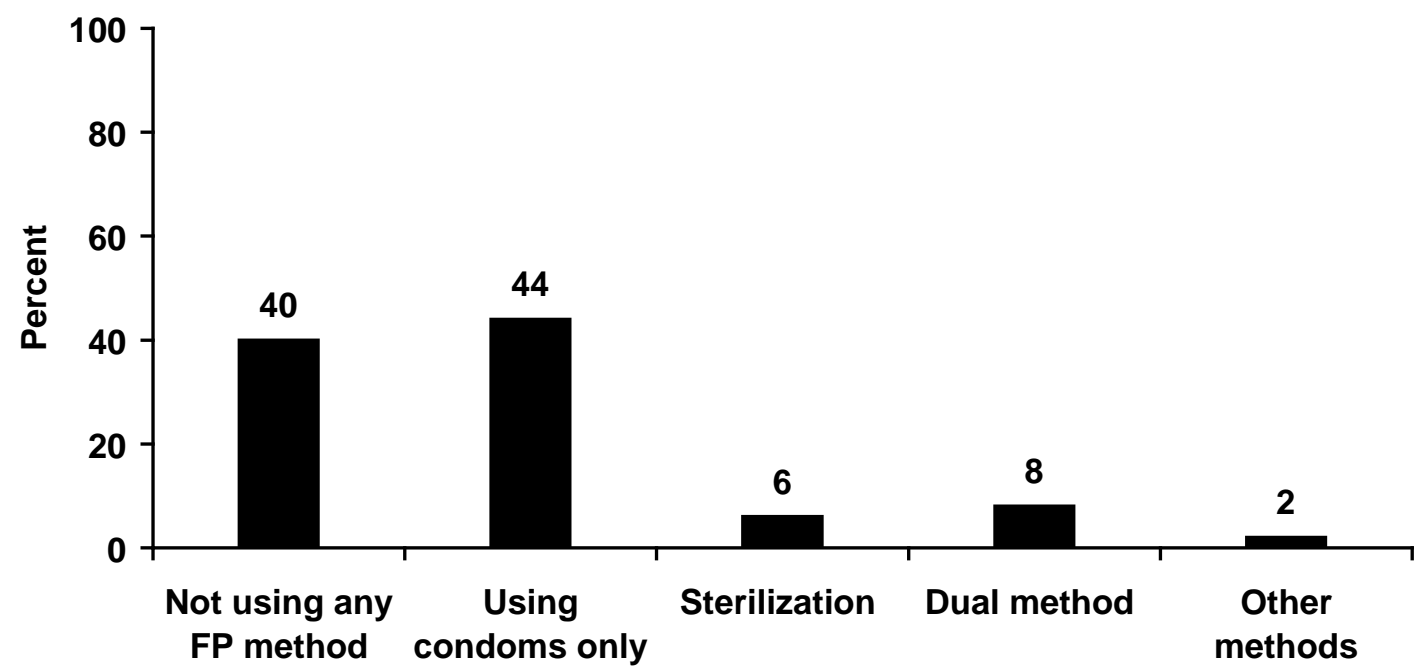

In some cases it appears that the provider's advice in favor of sterilization may be influenced by their opinion or views about the child's future as a potential orphan.

They [health care provider] said to have an operation and not to have another baby as we would leave them as orphans in this world-who will take care of them?

HIV-positive postpartum woman

Some of the women in the qualitative interviews mentioned using natural methods of pregnancy prevention, but this was not a major method that emerged from the quantitative data.

....when we join [sexual intercourse] there is a liquid [semen] that comes out of the man....at the end time he will leave the liquid [semen] out. Because of this the baby will not form. We are doing this now.

HIV-positive postpartum woman

\section{Safer sex and condom use}

Eighty percent of currently pregnant women $(n=97)$ mentioned that their PPTCT service provider advised them to use condoms during sexual intercourse with their partners during pregnancy.

... after I started going to the NGO clinic, their staff ask me whether I was using condoms. She told me that by using condoms I can prevent pregnancy as well as re-infection. I wasn't using anything 


\section{Hgrizons}

at that time. Nowadays we don't have sexual contact regularly. Even if we have we use condoms. I have condoms given by the NGO at home. We both decided on that. Like the way NGO staff talk to me, they talk to my husband also. So, it's a joint decision.

HIV-positive pregnant woman

However, only about two-thirds (65 percent) of these survey respondents reported that they and their partner were using condoms during sexual intercourse. There were no differences between women from the three cities. The reasons for not using a condom varied and included "no need to use with husband" and "husband does not like it."

I have never used [a condom] with my husband. We never felt the need to use and are not using now also.

HIV-positive pregnant women

My husband does not like using condoms so we do not use them.

HIV-positive pregnant woman

In qualitative interviews with pregnant and postpartum women, some mentioned that they were not always able to use condoms with their partners even though their service provider had counseled them so.

We do use condoms, but not always. We know it is best to use condoms but sometimes we forget and don't use it.

HIV-positive pregnant woman

...get condoms from the NGO and we used it quite often. But sometimes when my husband is drunk, I am not able to negotiate with my husband. And moreover I don't want to create chaos in the house fighting with him so I had to oblige.

HIV-positive pregnant woman

I never used condoms with my husband. With my sexual clients I have used it sometimes because they only wanted me to use condoms. Otherwise I never made an issue out of it. I know the NGO staff told us to use condoms always. But it is not always practical all the time.

HIV-positive postpartum woman and current drug user

Slightly more than 10 percent reported that they were advised by their counselor to abstain from sexual activity during pregnancy to prevent re-infection. Another 10 percent said that their PPTCT service provider did not provide any information about methods of preventing infection during pregnancy.

Not all women in discordant couples were using condoms. Of the 39 women who reported that the HIV test result of their husband was negative, 11 were pregnant and 28 were postpartum. Only 5 of the 11 pregnant women mentioned that they were using condoms to prevent transmitting HIV to their husbands. Among the 28 postpartum women whose husbands were HIV negative, 18 mentioned using condoms with their husband to prevent HIV transmission.

From the time I have been declared positive we have been using condoms. Because my husband is negative I don't want him to be infected.

HIV-positive pregnant woman 
We are using condoms for two reasons. One is not to have more children and the other is not to get my husband infected. I want him to live long.

HIV-positive postpartum woman

\section{Stigma, Discrimination, and Violence}

The respondents were asked about their views about people living with HIV. Of the 10 statements in the survey, four assessed attitudes toward HIV-positive women and six assessed support for the rights of people living with HIV in health care, workplace, community, and family settings. The results are presented in Table 13.

Most respondents (61 percent) agreed with the statement, "HIV-positive women should not marry.” But there was wide variation in support of this statement. Only 31 percent of women in Imphal felt that HIVpositive women should not marry whereas 82 percent of women in Hyderabad were in agreement. However, almost all respondents disagreed with the statement, "A man should leave his wife if she is HIV-positive.” Regarding childbearing and care giving, one-third of respondents (33 percent) were not supportive of HIV-positive women's rights to have children. However, once the woman had a child, a large majority (91 percent) felt that an HIV-positive mother should have the right to take care of her own children.

Table 13 Attitudes toward HIV-positive women

\begin{tabular}{|c|c|c|c|c|c|c|c|c|}
\hline \multirow[t]{2}{*}{ Statement } & \multicolumn{2}{|c|}{ Bangalore } & \multicolumn{2}{|c|}{ Hyderabad } & \multicolumn{2}{|c|}{ Imphal } & \multicolumn{2}{|c|}{ Combined } \\
\hline & $\begin{array}{c}\% \\
\text { Agree }\end{array}$ & $\begin{array}{c}\% \\
\text { Disagree }\end{array}$ & $\begin{array}{c}\% \\
\text { Agree }\end{array}$ & $\begin{array}{c}\% \\
\text { Disagree }\end{array}$ & $\begin{array}{c}\% \\
\text { Agree }\end{array}$ & $\begin{array}{c}\% \\
\text { Disagree }\end{array}$ & $\begin{array}{c}\% \\
\text { Agree }\end{array}$ & $\begin{array}{c}\% \\
\text { Disagree }\end{array}$ \\
\hline $\begin{array}{l}\text { A woman who is HIV-positive should } \\
\text { not marry }\end{array}$ & 61 & 39 & 82 & 18 & 31 & 69 & 61 & 39 \\
\hline $\begin{array}{l}\text { A man should leave his wife if she is } \\
\text { HIV-positive }\end{array}$ & 3 & 97 & 5 & 95 & 2 & 98 & 3 & 97 \\
\hline $\begin{array}{l}\text { A woman who is HIV-positive should } \\
\text { be able to have children if she } \\
\text { desires }\end{array}$ & 69 & 31 & 65 & 35 & 68 & 32 & 67 & 33 \\
\hline $\begin{array}{l}\text { A woman who is HIV-positive should } \\
\text { be allowed to take care of her } \\
\text { children }\end{array}$ & 89 & 11 & 82 & 18 & 95 & 5 & 91 & 9 \\
\hline
\end{tabular}

The respondents were asked about their views regarding HIV-positive people's rights to equitable and confidential health care in institutional settings (see Table 14). Overall, the vast majority of respondents agreed that an HIV-positive patient's status should not be shared with all health workers without prior consent, that HIV-positive people should be treated in the same hospitals as other patients, and that HIVpositive women should receive the same care as other patients in a hospital. There was also a great deal of support for HIV-positive people's right to continue in their jobs and to not put children of HIV-positive people in separate schools from other children. When asked whether HIV-positive persons should not be forced to disclose their status to their partner, there was more variation; only 55 percent of women in 


\section{Hgrizons}

Imphal felt this way whereas 93 percent of women in both Bangalore and Hyderabad supported this statement.

Table 14 Support for the rights of HIV-positive people in health care, workplace, community, and family settings

\begin{tabular}{|c|c|c|c|c|c|c|c|c|}
\hline \multirow[t]{2}{*}{ Statement } & \multicolumn{2}{|c|}{ Bangalore } & \multicolumn{2}{|c|}{ Hyderabad } & \multicolumn{2}{|c|}{ Imphal } & \multicolumn{2}{|c|}{ Combined } \\
\hline & $\begin{array}{c}\% \\
\text { Agree }\end{array}$ & $\begin{array}{c}\% \\
\text { Disagree }\end{array}$ & $\begin{array}{c}\% \\
\text { Agree }\end{array}$ & $\begin{array}{c}\% \\
\text { Disagree }\end{array}$ & $\begin{array}{c}\% \\
\text { Agree }\end{array}$ & $\begin{array}{c}\% \\
\text { Disagree }\end{array}$ & $\begin{array}{c}\% \\
\text { Agree }\end{array}$ & $\begin{array}{c}\% \\
\text { Disagree }\end{array}$ \\
\hline $\begin{array}{l}\text { 1. The status of an HIV-positive } \\
\text { patient should not be shared with } \\
\text { all health workers in a hospital } \\
\text { without his/her consent }\end{array}$ & 97 & 3 & 76 & 24 & 88 & 12 & 87 & 13 \\
\hline $\begin{array}{l}\text { 2. People who are HIV-positive } \\
\text { should not be treated in the same } \\
\text { hospital as other patients }\end{array}$ & 5 & 95 & 16 & 84 & 6 & 94 & 9 & 91 \\
\hline $\begin{array}{l}\text { 3. A woman who is HIV-positive } \\
\text { should receive the same care as } \\
\text { other patients in a hospital }\end{array}$ & 99 & 1 & 90 & 10 & 94 & 6 & 94 & 6 \\
\hline $\begin{array}{l}\text { 4. People who are HIV-positive } \\
\text { should be asked to resign from } \\
\text { their jobs so that they don't infect } \\
\text { their co-workers }\end{array}$ & 2 & 98 & 10 & 90 & 1 & 99 & 4 & 96 \\
\hline $\begin{array}{l}\text { 5. Children of HIV-positive people } \\
\text { should go to separate schools from } \\
\text { other children }\end{array}$ & 2 & 98 & 6 & 94 & 3 & 97 & 4 & 96 \\
\hline $\begin{array}{l}\text { 6. HIV-positive persons should not } \\
\text { be forced to disclose their status to } \\
\text { their partner }\end{array}$ & 93 & 7 & 93 & 7 & 55 & 45 & 83 & 17 \\
\hline
\end{tabular}

\section{Internalized stigma and perceived interpersonal discrimination}

Analysis of scores from the adapted 20-item stigma scale revealed that a little more than a fourth of the women had a high level of internalized stigma and perceived interpersonal discrimination, while the majority (66 percent) had a moderate level (see Figure 13). But only 2 percent of women in Imphal had a high level of internalized stigma compared to more than a third of the women in the other two sites. 
Figure 13 Level of internalized stigma and perceived interpersonal discrimination

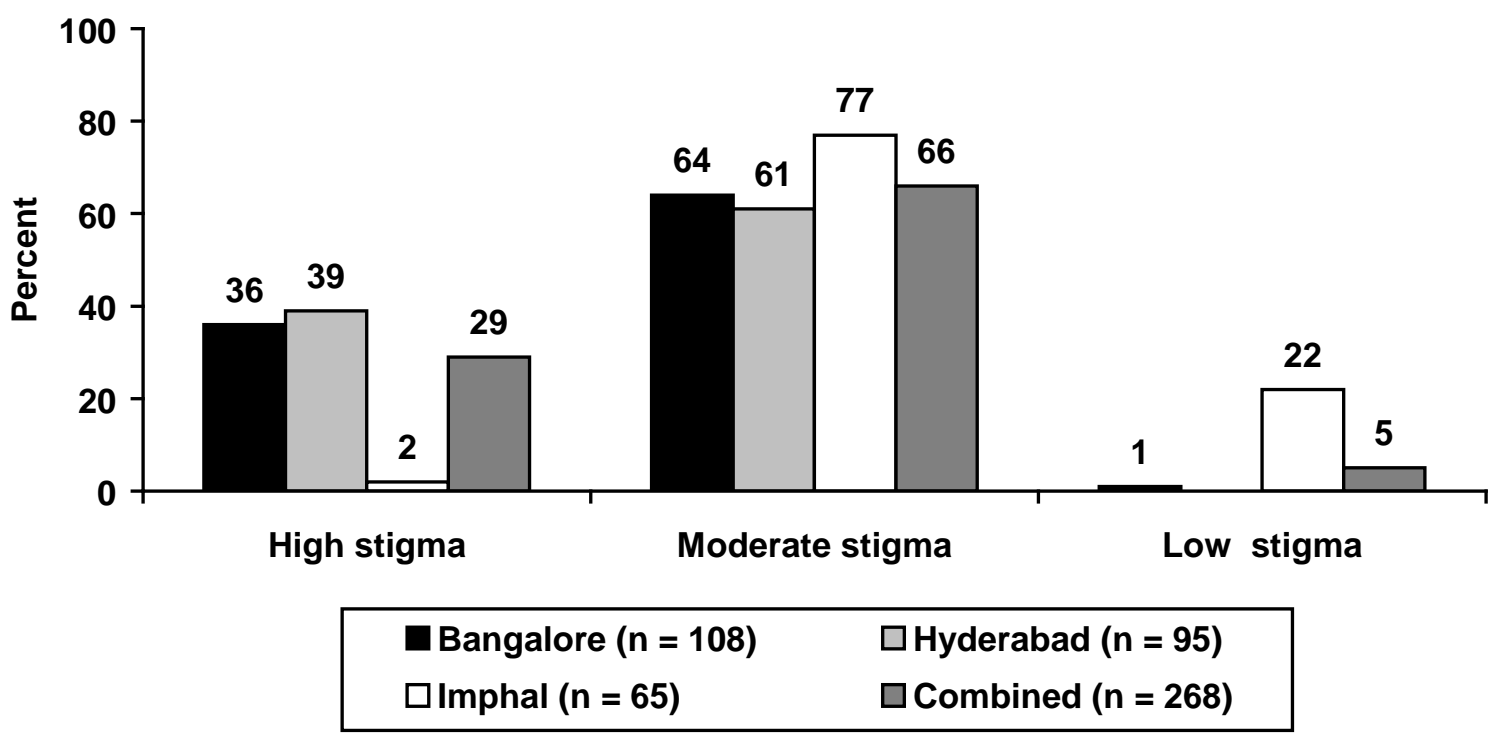

A high level of stigma was also observed in the qualitative interviews with both HIV-positive pregnant and postpartum women. Some of the women described their perceptions of how people would react to them if they learned the women's HIV status.

People will look down upon us is also one more reason for not disclosing to others.

HIV-positive postpartum woman

We know how people will look upon us, nobody will like to be close to us, so we decided not to disclose to anyone.

HIV-positive pregnant woman

I did not disclose my status to the doctor because I had the fear whether he will see me or not.

HIV-positive pregnant woman

\section{Experienced stigma and discrimination}

Most respondents who had participated in the qualitative research reported perceiving and experiencing discrimination against them while seeking health care.

...during my stay in the hospital, I noticed that the ward nurses were ignoring me. None of them wanted to do my dressing or to give me injections. I could see that they were pushing one another to attend to me. It was very humiliating and I felt bad. I didn't tell my status but I think they all knew. I was satisfied with the care given by Dr... but not by the nurses. I didn't want to stay there for long.

HIV-positive postpartum woman 


\section{Hgrizons}

...during my delivery, the nurse was very scared to touch me. They discharged me immediately after my delivery even though I was very weak and unwell.

HIV-positive postpartum woman

After knowing my HIV-positive status, they just check us from a distance, just see like that and send away without saying anything. They also don't give any tablets.

HIV-positive pregnant woman

I have noticed the difference in the way they treat us and other patients. When the come to us they wear gloves and also call us " $Z$ " cases. They also wrote " $Z$ " on my case sheet.

HIV-positive pregnant woman

But it is very sad that the hospital here refused to do the operation [sterilization] as I was positive.

HIV-positive postpartum woman

When I went to the hospital for my abortion and informed the doctors and nurses about my status, they spoke to me very harshly and told me "who told you we are doing abortion here? Who sent you here-go away." They spoke to me very badly and I decided not to get my abortion.

HIV-positive pregnant woman

As soon as the doctors were told that I was HIV-positive they did not give me a bed to sleep. The whole night I was on the floor outside the ward even though a lot of beds in the ward were empty. I cried throughout the night.

HIV-positive post partum woman

Some of the women also described negative experiences with family and friends after they shared their HIV serostatus with them.

In the beginning I disclosed to my parents...they started to look down upon me. I also disclosed to one of my close friends but after knowing she started keeping distance. My parents, sisters they said "keep distance from them [my family] keep their plate and glass separate." So now I don't go to their house.

HIV-positive postpartum woman

I have harassment at house by sisters and brothers... they use to say, "you have AIDS so you will die soon," such kinds of things happened. I felt very bad and very unhappy.

HIV-positive pregnant woman

My husband has two brothers and we all live together in the same house though we have separate kitchens. Even if they can't help us financially they don't also give us mental or physical support. Instead they discriminate my children. They don't want my children to play together with their children [she started crying while telling this]. I could not tolerate all nonsense so I fought with everyone in the family. I am not in talking terms with any of them.

HIV-positive pregnant woman 
However, not all experiences were negative. There were some women who had positive experiences after they disclosed their serostatus to family members or to health care providers. One woman talked in detail about her positive feelings since she was diagnosed HIV-positive.

At first when I came to know of this, I was very upset. Also had a lot of pain and hurt. Now after my child is born, I feel how nice my life is. My husband too is taking good care of me. We have a lot of support. Nobody looks down upon us. When we go to any hospital we will tell about our HIV condition and then only take treatment. No doctor also has looked down upon us. All of them give courage. We are explained that, for good health, any time when we fall sick, whatever it may be we must go for immediate treatment then we can protect our health.

HIV-positive postpartum woman

\section{Violence}

Eighty-seven percent of women (209/239) currently living with a husband or partner reported that he was aware of their HIV serostatus. Among these women, 12 percent (26) reported ever experiencing some form of violence from their current partner. Half (13) experienced physical violence since they were diagnosed HIV-positive, and of these, eight were women whose husbands had tested HIV-negative or did not know their status. Most of the women had experienced verbal abuse (20/24); 10 reported sexual violence. Women were asked to give a reason for their husband's violent behavior toward them. Most said that they were either blamed for the disease or were suspected of having had an affair with another man. The remainder said their husbands were violent when they were under the influence of alcohol.

After sharing my HIV status to my husband, he beats me and blames me that he has got the disease because of me. Rest of the people are good to me.

HIV-positive pregnant woman

My husband's words were very painful. He said there is no life for you now. You will die very soon. You have no future. You have ruined my children.

HIV-positive postpartum woman

After knowing I have this disease he [my husband] started troubling me a lot. He blames me that he is got HIV-positive because of me. So I left him and I am living with my mother now because of this issue.

HIV-positive postpartum woman

He always drinks and abuses me saying that "you go die somewhere. Because of you I am having lot of problems." He always blames me that I have that disease. He always beats me.

HIV-positive postpartum woman

He [my husband] is suspecting me. How did I get this? From whom I have got this? He beats me because of this.

HIV-positive postpartum woman 


\section{Hgrizons}

\section{Enhancing Linkages and I mproving Access to Services}

\section{Perspectives of HIV-positive women}

The women who participated in in-depth interviews were asked for their suggestions for improving their and their family's access to HIV treatment and care services. Some of the women wanted more interaction with health care workers and counselors, but at home.

Health workers should come home. Sometime when we are really sick and weak we cannot travel, we need the help of health workers to come to our house.

HIV-positive postpartum woman

We cannot always come here [the hospital] so if the counselors come home to inquire about us and our health problems it would be very convenient.

HIV-positive postpartum woman

The survey respondents also shared their views about health care workers conducting home visits to provide services. Half of the women felt that health workers should visit them in their homes, but as friends and not as health providers or else everyone in the community would become aware of their status. The other half did not want health workers to visit them at home in any capacity; they worried about potential disclosure of their status to other family members as well as community members.

I would like to take the services if provided by visiting my house. But I want the particular person to come to my house as a friend. If everyone comes to know it will not be good.

HIV-positive postpartum woman

I am already suffering so much. People at home are always cursing me for everything. Others' mistakes are also given my name. If someone comes and talks it will become hell for me. They will never tolerate anybody coming home and supporting me. So it is better no one comes and let me live my life as it comes.

HIV-positive postpartum woman

People around my house ask a hundred questions. Who is she? Why has she come? etc. They will start doubting so I do not want anyone to come to my house. If necessary I will come and take the treatment.

HIV-positive pregnant woman

Women suggested that it was important to address stigmatizing attitudes and discriminatory practices toward HIV-positive people by health care providers and the community. One woman recommended that the curriculum for school and college students include sensitization lessons as well as accurate information about HIV transmission.

I would like to tell that they should not look down upon us in the hospital-that is very important. I feel this sensitivity should be introduced in lessons in college for doctors. Do's and don'ts should 
be taught in schools so that from a young age children are given awareness about HIV/AIDS. Even today people think it is only from sex so total awareness should be given to children at high school and college level.

HIV-positive postpartum woman

Most survey respondents mentioned the need for expanded treatment and medical care for themselves and their children.

Medicine and diagnostic supports. I want them to guide me in the proper way for my good health. HIV-positive pregnant woman

I want medical care and nutrition support for my children.

HIV-positive pregnant woman

Nutrition, medicine, and psychological supports. I want more medicine support.

HIV-positive postpartum woman

One woman endorsed the need for opening more care and support centers for ensuring that HIV-positive people get specialized care.

\section{Perspectives of service providers}

Some service providers identified gaps in existing services and suggested ways of addressing them. For example, one talked about the limitations of the current PPTCT program in terms of linkages with pediatric treatment and care.

As a PPTCT program we do not have any elaborate guidelines for pediatric AIDS. The pediatric AIDS issues need to be elaborately defined. Even today there are no such drugs for children. If you have a child the child cannot be given the same tablet which the mother gets. We have to give in the form of drops and to very small infants we give in the form of syrups. For children who are HIVpositive, even today we do not have those syrups or drops.

Program manager

After this study was completed, National Pediatric Guidelines were developed and launched. With support from the Clinton Foundation, the government has procured pediatric formulation for infants that will be provided through the PPTCT program sites.

The same service provider also shared her views about integrating HIV/AIDS and sexual and reproductive health services.

The integration of HIV/AIDS, reproductive and child health $(\mathrm{RCH})$ and family planning has happened in Karnataka by virtue of an order which was issued by the commissioner of health. Last year for an Auxiliary Nurse Midwife in a family health center in the list of issues she has to address in the monthly reporting format we have included 2 or 3 items which pertain to HIV/AIDS. So to that extent there has been an integration between HIV/AIDS at least on paper, but the actual integration in terms of systems has not happened. RCH itself is a very vertical program. Also a lot 


\section{Hgrizons}

of money coming in from the government of India for HIV/AIDS is also for vertical programming. So integration of these two vertical programs is not an easy thing and will take time.

Program manager

Another service provider discussed the need to expand the reach of the existing PPTCT program to women who don't access the public sector for antenatal care. She also mentioned the need to pay particular attention to women who travel to their natal home for delivery away from the site they received antenatal care, and to document what the women who receive Nevirapine to take with them do.

To reach to women who don't come to hospitals should be thought about. At least in hospital settings we know we are giving the tablets to the mothers who come for the ANC check up and are tested positive. But you know in many parts of India the women go to their maternal home for delivery. So there it is difficult to get those people at the time of delivery and administer the Nevirapine. So there are some centers who give the Nevirapine tablets to the mothers to take with them to their maternal home so that wherever they go to the hospital at the time of delivery 2 to 4 hours before the labor pain starts they can take the medicine. This system is not well documentedin the sense are the women able to remember to take the medicine at the time of labor when the pain starts. So that is not NACO policy. In fact, ideally we should encourage those women to contact the PPTCT center next to her parental home where they go for this delivery and have delivery at those centers. As there is uncertainty about sending those tablets so it is not a policy. We should have good network of the PPTCT centers so that the counselor knows which center to refer the woman to at her parental/maternal home in another Taluk [block level] hospital or anther district.

Service provider

Service providers also offered detailed suggestions for improving uptake of pediatric HIV testing.

One of the main reasons for poor pediatric care follow-up is that the mother goes somewhere else for delivery. After the period of 3 months they come back, then what is the incentive to come for a follow up. Basically most of those mothers are in the early stage of the HIV infection, they might not be in the advanced AIDS stage in where they come to hospital. Now they don't have any symptoms. What is there is they should accept their status and bring the child at 18 months. So we do face lot of problems in follow-up for testing children after 18 months. Many mothers drop out here-we have 10 percent follow-up rate. Almost 90 percent of people don't come back for follow up. Maybe the system has to be again a well oiled machinery which motivates mothers to come not as part of a follow up for HIV testing but as part of a immunization for the child. Now you know about immunization at 18 months, MMR is given at 18 months. So make this as a part of the package for the child who comes for an immunization and also test for HIV.

Service provider

See for linkages between PPTCT and the pediatric ward there is a very glaring defect of the existing system. The pediatric people who follow-up the child are not linked with the PPTCT counselor. So those barriers should be broken. Fortunately testing doesn't happen in the pediatric ward and in the pediatric OPD but it happens in the gynecology department's ANC clinic. So there should be a linkage so when this child comes for 18 months or for some immunization there the pediatrician should be motivated to send the child for HIV testing.

Service provider 
Service providers also discussed enhancing linkages with HIV treatment centers, a key gap in the current program. According to one informant:

Right now that is not well established. First of all, there are only few centers so when you have an ART center in each district hospital there the linkage will be very strong. If there is a positive person we ask her to go there to have her CD4 count tested to find out if she is needy for treatment. There may be a hospital 300 to 400 kilometers away which is giving ART she needs to be motivated to go and take. I think that is just a matter of time when these ART centers will appear in smaller towns located in the district hospitals. I think those linkages will be established then. The linkage between a pediatric department and an obstetric and gynecology department in the same hospital is based on crossing a mental and physical barrier. This requires some awareness about the importance of this issue.

Service provider 


\section{Hgrizons}

\section{Discussion and Recommendations}

This study, one of the first in India to examine the efforts of PPTCT programs in different cities to offer women a continuum of care, shows that the programs have both strengths and shortcomings. In terms of their strengths, the PPTCT programs in Bangalore and Hyderabad have provided women with an opportunity to learn their HIV status. The data suggest that the programs' counseling sessions have been successful in helping HIV-positive women disclose to their husbands and to encourage their husbands to get tested as well. Thus, the PPTCT programs in these sites have succeeded in testing and counseling married men who may not otherwise access HIV counseling and testing services. In Imphal, most women were the partners of injecting drug users and were often diagnosed HIV-positive after their husbands learned their own positive serostatus. Given their vulnerability to HIV infection because of their husbands' and, for some, their own injecting drug practices, the NGO-supported PPTCT programs examined as part of this study play an important role in preventing vertical transmission

Another strength of the PPTCT programs is that health providers are emphasizing ways to prevent HIV transmission to infants during delivery, labor, and infant feeding. During counseling sessions, they are informing women about and providing women and infants with medications to prevent vertical transmission. More than nine out of 10 women surveyed took Nevirapine or AZT; a smaller yet still high percentage of women who had a live birth (86 percent) said their infant received medicine to prevent HIV infection. Women are also receiving infant feeding counseling that stresses the importance of choosing an exclusive method as evidenced by just 7 percent reporting that they are practicing mixed feeding. In addition, health workers are advising HIV-positive women on ways to prevent re-infection during pregnancy, including using condoms and abstaining from sex. Only 10 percent of women said their PPTCT provider said nothing about how to prevent re-infection.

But the study also highlights a number of missed opportunities. Overall, less than half the women had heard of treatment for HIV. During ANC in particular, less than a third of women were informed about the CD4 test and only 18 percent about ARVs. Of the 19 women on ART in the study, just two had been referred for treatment by their PPTCT provider. But awareness and access to HIV treatment varied by city. The majority of women in Imphal were aware of CD4 testing and ARV treatment and most of the women on ART in the study were from there. One reason to explain this is that most of the PPTCT clients from Imphal were also enrolled in HIV treatment and care programs that provided information and follow-up services to women and their families. This was not the case in Bangalore and Hyderabad where the programs focused solely on providing PPTCT services despite the fact that ART was available in each of these cities and from some of the same facilities where the PPTCT programs were being implemented. The findings by city suggest that women who start out as clients of a care and support program are more

likely to get a continuum of care when they become pregnant because of the likelihood that they would be referred to a PPTCT program, compared to women who are first PPTCT clients, because referrals to treatment and care services for them are less common. Thus, PPTCT programs need to do a better job of linking with services that provide HIV treatment, care, and support, including those provided by NGOs, so that women and their families are more likely to receive a continuum of care.

Involvement of NGOs with strong outreach programs in PPTCT programs can benefit the women's children as well. The study found that PPTCT clients from the NGO-supported sites were more likely to have had one or more of their children tested compared to women getting services from the public sector. The test was most often recommended by the service provider and was usually done as part of PPTCT 
services. In the study sample, most of the women enrolled through the NGOs were in regular contact with the project outreach team until their children were 24 months old. This highlights the need for effective outreach to ensure that children are tested, diagnosed, and treated appropriately. Also, outreach team members need to encourage women to test all their children for HIV and not only those born after they are diagnosed with HIV.

The focus of PPTCT programs is to prevent HIV transmission from mother-to-child; thus, the program's prime interaction with women occurs during pregnancy. But it is also during the postpartum phase that prevention efforts can achieve successful results if the family planning needs of couples are met. Although most women mentioned that their current or most recent pregnancy was planned, the majority said that after they became aware of their serostatus they did not want to have any more children. But a significant proportion of these women were not using any family planning method to prevent unwanted pregnancies. Interviews with HIV-positive women revealed that some providers strongly recommended that they adopt a permanent method of family planning. But this sometimes occurred without the providers taking into account the women's particular needs and desires. Instead providers should counsel clients on the benefits of dual protection to prevent pregnancy and re-infection, and ways to enlist the women's husbands in supporting the adoption of appropriate family planning methods. Couples who opt for permanent methods should also be encouraged to use condoms. Dual protection counseling is particularly important for sero-discordant couples, not only to prevent unintended pregnancies but also to prevent transmission to a negative partner.

The findings on stigma and discrimination have implications for how PPTCT services need to be delivered. The study found that some women had been refused services once their status was known by health providers or had been provided with inferior or stigmatizing care. A significant proportion of women had a high level of internalized stigma and perceived discrimination and this could influence their utilization of other health or support services. For example, many women were wary of support groups for HIV-positive people because of fear that their status would become known in the community. In addition, women reported experiencing stigma and discrimination from their extended family and community members. Perceived stigma was an important factor in women's choice of infant feeding, and sometimes it interfered with their ability to provide exclusive replacement feeding, resulting in mixed feeding, a more dangerous option. These findings highlight that all health facilities in India providing PPTCT services need to have policies in place that do not prevent HIV-positive women from receiving care and that health workers need to be trained and sensitized on how to provide services that are non-stigmatizing. PPTCT providers also need to learn how to help women cope with real and perceived stigma in their lives, including violence, which is an extreme form of stigma. If providers are unable to address these complex issues, referral networks should be established to ensure women have access to appropriate services.

In conclusion, the study indicates that linkages between PPTCT and HIV care services, as well as PPTCT and reproductive health services, are limited. To overcome these shortcomings, the PPTCT programs studied should strengthen their referral systems to public and private treatment and family planning services, better equip PPTCT providers to inform and counsel women about these topics, and engage NGOs in the community who have outreach services to not only enroll more women for availing PPTCT services but also to maintain contact with women over time and link them and their families to a continuum of care. 


\section{Hgrizons}

\section{References}

Indian Academy of Pediatrics (IAP) and National AIDS Control Organization (NACO). 2006. “

Guidelines for HIV Care and Treatment in Infants and Children.” New Delhi: NACO

National AIDS Control Organization. 2004. “Annual report.” New Delhi: NACO.

—. 2006. "Facts and figures_-Monthly updates on AIDS (31 August 2006)."

http://www.nacoonline.org/facts_reportaug.htm.

Personal communication with National PPTCT Consultant, NACO. 2005.

Rutenberg, Naomi and Carolyn Baek. 2004. "Review of field experiences: Integration of family planning and PMTCT services.” Washington, DC: Population Council.

UNAIDS/UNFPA/UNIFEM. 2004. "Women and HIV/AIDS: Confronting the crisis. A joint report by UNAIDS/UNFPA/UNIFEM.” Geneva/New York: UNAIDS/UNFPA/UNIFEM.

UNAIDS/WHO. 2006. “AIDS epidemic update:December 2006.” Geneva: UNAIDS.

UNICEF. 2006. "UNICEF India-Children's issues: HIV/AIDS.”

http://www.unicef.org/india/children_2358_htm.

—. 2007. "India— UNICEF HIV and AIDS Programming Country Profile 2006.”

http://www.unicef.org. 


\section{Appendix 1}

\begin{tabular}{l} 
Key elements \\
\hline 1. Training of health \\
functionaries in ANC \\
setting \\
2. Voluntary \\
counseling and testing \\
for ANC attendees
\end{tabular}

\section{HIV testing and counseling for spouse/partner}

\section{Nutritional counseling and support \\ 5. ARV prophylaxis for HIV+ woman}

\section{National PPTCT Program}

1. Training of health functionaries in ANC setting

2. Group education and once consent provided conduct pretest and post-test counseling for ANC attendees

3. HIV testing and counseling for spouse/partner

4. Nutritional counseling

5. Single dose NVP $200 \mathrm{mg}$ at onset of labor

\section{ARV prophylaxis for infant}

6. NVP $2 \mathrm{mg} / \mathrm{kg}$ body weight oral suspension immediately after birth and within 72 hours

\section{EGPAF-supported PPTCT program}

1. Training of health functionaries in ANC setting

2. Group education and once consent provided conduct pre-test and posttest counseling for ANC attendees

3. HIV testing and counseling for spouse/partner

4. Nutritional counseling and support

5. A) Antentatal: AZT 200-300mg (depends on body weight) twice a day during pregnancy; start by 14 weeks of gestation (minimum for 4 weeks)

AND

B) Intrapartum: AZT 300mg at onset of labor and every 3 hours until delivery

OR

Single dose NVP 200mg at onset of labor

6. AZT $4 \mathrm{mg} / \mathrm{kg}$ body weight twice a day for 7 days

OR

NVP $2 \mathrm{mg} / \mathrm{kg}$ body weight oral suspension immediately after birth

OR

(When mother has not received ARV prophylaxis) NVP $2 \mathrm{mg} / \mathrm{kg}$ body weight oral suspension immediately after birth and AZT 4mg/kg twice a day for 7 days

OR When AZT oral suspension not feasible NVP $2 \mathrm{mg} / \mathrm{kg}$ as soon as possible after delivery and a dose of NVP 72 hours after birth 


\section{Hgrizons}

\section{Infant feeding} counseling

8. HIV testing for infant
7. As per WHO

recommendations: provide

counseling on pros and cons of different feeding methods. Advice on exclusive breastfeeding till infant turns 3 months followed by immediate cessation of breastfeeding and start up of weaning food.

8. ELISA test when infant is 18 months old
7. As per WHO recommendationsprovide counseling on pros and cons of different feeding methods. Advice on exclusive breastfeeding till infant turns 3 months followed by immediate cessation of breastfeeding and start up of weaning food.

\section{PCR-}

One test when child is 4 months old if on exclusive replacement feeding from birth

\section{OR}

ii) If breastfeeding, then PCR test 2 months after abrupt cessation of breast milk

OR

ELISA test when infant is 18 months old 


\section{Hgrizons}

Horizons is a global operations research program designed to:

- Identify and test potential strategies to improve HIV/AIDS prevention, care, and support programs and service delivery.

- Disseminate best practices and utilize findings with a view toward scaling up successful interventions.

\section{(2) Population Council}

Horizons is implemented by the Population Council in collaboration with

- International Center for Research on Women (ICRW)

- International HIV/AIDS Alliance

- PATH

- Tulane University

- Family Health International (FHI)

- Johns Hopkins University

For more information, please contact:

Horizons Program, Communications Unit 4301 Connecticut Avenue, NW Suite 280 Washington, DC 20008 USA

Tel: 202-237-9400

Fax: 202-237-8410

Email: horizons@popcouncil.org www.popcouncil.org/horizons 